\title{
PAPIERCHROMATOGRAPHISCHE UNTERSUCHUNGEN AN BLÜTENHONIGEN UND NEKTAR
}

\author{
Dr. A. MA URIZIO \\ Bienenabteilung, Liebefelcl-Bern.
}

\section{EINLEITUNG und FRAGESTELLUNG}

Det Honig wird von Biencen aus zuckerhaltigen Rohstoffen, vor allem Nektar und Honigtau hergestellt. In der 'Trockensubstanz des Honigs und seiner Rohstoffe herrschen Kohlehyclrate weitgehend ror. iiber deren Zusammensetzung jedoch bis vor kurzen wenig bekannt war. Der Nektar galt als wässerige I, ösung ron Iiruktose, Cilukose und Saccharose; in Honigtau wurden ansserdem Melezitose, Jexitrine, I) tlcit und Mannit nachgewiese1]. Als Haupthestandteile des Honigs wurden Invertzucker (Iiruktose und (Glukose), Saccharose und eine als " Honigdextrine "bezeichnete Gruppe nicht näher bekannter Kohlehydrate. in Honigtanhonigen ansserdem IIelezitose festgestellt. Feltener wurden Maltose und I'entosane als Honigbestandteile genannt (Bartels, Beutler. Beutler und Schöniag, Beutler and Wahl, Bonnier, i'. Fellenberg, i. Fellenberg und Kuffy, Geinit:, Gorbach, Notbohm und Lucius, ‘. Planta usa'.).

lirst die Einführung netter Intersuchungsmethoden, vor allem der Papierchromatographie erlaubte eine bessere Firfassung der ju Honig und seinen Rohstoffen enthaltenen Kohlehydrate. Es zeigte sich, lass der Nektar verschiedener Pflanzenarten, neben Fruktose, Glukose, und Saccharose, oft Iraltose und eine Reihe höhermolekularer Zuckerarten enthält, und dass in Honigtau regelmässig 'I'ri-und Olignsaccharide rorkommen. Anch das Zuckerbild des Honigs erwies sich als wesentlich reichhaltiger als früler angenommen wurde. Vorherrschend sind stets Fruktose and Glukose; selur häufig ist Maltose rorhanden, während saccharose in wechselnden Mengen auftritt und oft ganz fehlt. Melezi- 
tose ist für gewisse, jedoch nicht für alle Honigtanhonige charakteristisch. Ausserdem enthält dje Mehrzahl der Blïten-tund Honigtatuhonige 3-5 oder mehr, höhermolekulare Zuckerarten, die im Chromatogranm Flecke mit niedrigen $\mathrm{R}_{\mathrm{F}}$-VTerten bilden und bisher nur teilweise identifiziert werden konnten (Austin, Duspiva I953, I954 a, b, Ewart und Metcalf, Furgala, Gochnaner und Holdaway, Goldschmidt und Burkert, Gray, Gray und Fränkel 1953, I954, Malyoth, Maurizio I954a, b, Täufel und Milller, Täufel und lieiss, White 1952, 1957, White und Maher 1953a, b, 1954, Wolf und Ewart, Wykes 1952, I953, Zimmermann I953, 1954, Zusshii).

I)as Zuckerspektrum des Honigs und seiner Rohstoffe wird erst verständlich, wenn man ihre İntstehung in Betracht zieht. Nektar wie Honigtau stammen ursprünglich aus dem Phloemsaft höherer Pflanzen und werden durch pflanzliches I)rüsengewebe (Nektarien), oder durch Vermittlung saugender Insekten abgesondert. Bei gewissen Pflanzenarten enthält der Phloemsaft nur Saccharose (z. B. Robinia psendacacia, Acer platanoides, A. saccharm, Quercus-Arten), bei andern (z. B. Ailanthus altissima, Fraximus americana, Carya oata) sind ausserdem Iiruktose, Glukose, Stachyose und Verbascose nachgewiesen worden (Parker, Ifanner I953 a, b, Ziegler Zimmermann I957 a, b, I958 a, b). Nach Parker ist zudem die chemische Zusammensetzung des Phloemsaftes jahreszeitlichen schwankungen unterworfen, so dass bei der gleichen Pflanze im sommer nur Saccharose, in Winter ausserdem andere Zuckerarten auftreten können.

Unter dem Iinfluss zuckerspaltender liernente der Nektarien und der Honigtauerzenger unterliegen die Kohlehydrate schon in den Rohstoffen weitgehenden Veränderungen. Weitere enzymatische Vorgänge spielen sich bei der Aufnahme der Rohstoffe durch die Biene und während des Honigreifungsprozesses im Bienenvolk ab. Bei der Honigbereitung mengen die Bienen den aufgenommenen Rohstoffen körpereigene Fiermente bei, die zur Hanptsache aus den Pharynxdrüsensekret stammen und die Fähigkeit besitzen Saccharose, Maltose, Melezitose, Melibiose, Raffinose, I'Tehalose und Jextrine, unter Bildung verschiedener Abbauprodukte zu spalten (Contarski, Maurizio I957, I959, dort weitere Iiteratur). So stellt das Zuckerspektrum des Honigs das Indprodukt eines komplexen enzymatischen Vorganges dar, an den pflanzliche und tierische Karbohydrasen beteiligt sind.

Nach neneren Arbeiten sind pflanzliche, wie tierische Karbohydrasen nicht nur zur sjaltung höherer Zuckerarten in einfache befähigt, sondern auch zur gleichzeitigen synthese von ()ligosacchariden nach den Prinzip der (iruppenübertragung. I)er Ablauf der Hydrolyse and ihre Produkte sind rom Charakter der dabei wirksannen liermente abhängig. So verläuft z. B. die Hỹdrolyse ron Rohrzucker durch Saccharase aus 
Hefen and schimmelpilzen und aus den Knollen von Helianthus tuberosus auf dem Wege einer Transfruktosidierung, während die liemente aus Honig, den Darmextrakten von Bienen und Aphiden und aus dem Nektar von Robinia pseudacacia eine Transglukosidierung herbeiführen. Der Verlauf der Rohrzucker-Hydrolyse lässt sich aus den dabei entstandenen Produkten beurteilen, d. h. aus dem Bat der Oligosaccharide und aus dem Nengenverhältnis zwischen Glukose und Iruktose. Während bei Transfruktosidierung der firuktoserest auf andere anwesende Zucker übertragen wird, wobei sich fruktosehaltige Oligosaccharide bilden und im Substrat freie Glukose angereichert wird, entstehen bei Transglukosidierung glukosehaltige Oligosaccharide, bei gleichzeitiger Aureicherung ron liruktose. Aehnliche lorgänge finden bei der Hydrolyse von Maltose and I actose statt (Bacon I952, 1954 a, b, Bacon und Dickinson, Bacon and Edelmann, 1950, I951, Bealing, Bealing und Bacon, Blanchard und Albon, Duspica 1953, 1954 a, b, Manrizio I954 a, b, 1957, 1959, Pazur and French, Wallenfels und Bernt, Wallenfels, Bernt und Limberg, White I952, 1957, White und Waher $1953 a, b$, Zimmermann 1953, I954, dort weitere I,iteratur).

I) an der Hydrolyse der Saccharose, in der Zeit zwischen der Absonderung der Rohstoffe und der Ernte des Honigs mehrere pflanzliche und tierische Saccharasen beteiligt sind, stellte sich die Irage, wieweit der Finfluss der einzelnen (ilieder dieser Abbaukette in Endprodukt noch erkennbar ist. Anders formuliert lautet die lirage: ist das Zuckerspektrum des Honigs vorwiegend ein Produkt der Bienenfermente, oder 1ässt sich darin das urspüngliche Zuckerbild der Rohstoffe erkennen? Nimmt man an, dass die Bienenfermente den Haupteinfluss auf die Zusammensetzung der Zucker in Ho:ng ausüben, so wäre zu erwarten, dass alle Ho:nige, unabhängig von ihrer Herkunft übereinstimneade Zuckerbilder besitze: spielen dagegen neben den Bieneninvertase:1, anch die Fermente des Nektars und des Honigtaus bei der Gestaltung des Zuckerbilds des Honigs eine Rolle, so wären charakteristiche Unterschiede zwischen Honigen verschiedener botanischer Herkunft zu erwarten.

Schon die ersten von mir ausgeführten Voruntersuchnngen liesse: erkennen, dass die Chromatogramme verschiedener Naturhonige zwar im I'rinzip ausgeglichene Zuckerspektren aufweisen, dass sich darunter aber, je nach der botanischen Herkunft gewisse charakteristiche Typen abzeichnen. J)ie Abbildungen I und 2 illustrieren diest Beobachtung. ie zeigen Chromatogramme von 4 schweizerhonigen verschiedener Herkunft : Abb. I einseitige Raps-und Akazienhonige, Abb. 2 einen Blütenmischhonig and einen in der Wabe kandierten Rottannenho:aig. Eer Rapshonig besitzt praktisch nur zwei Zuckerarten, liruktose und Glukose, während saccharose und IIaltose als sehr schwache, knapp 

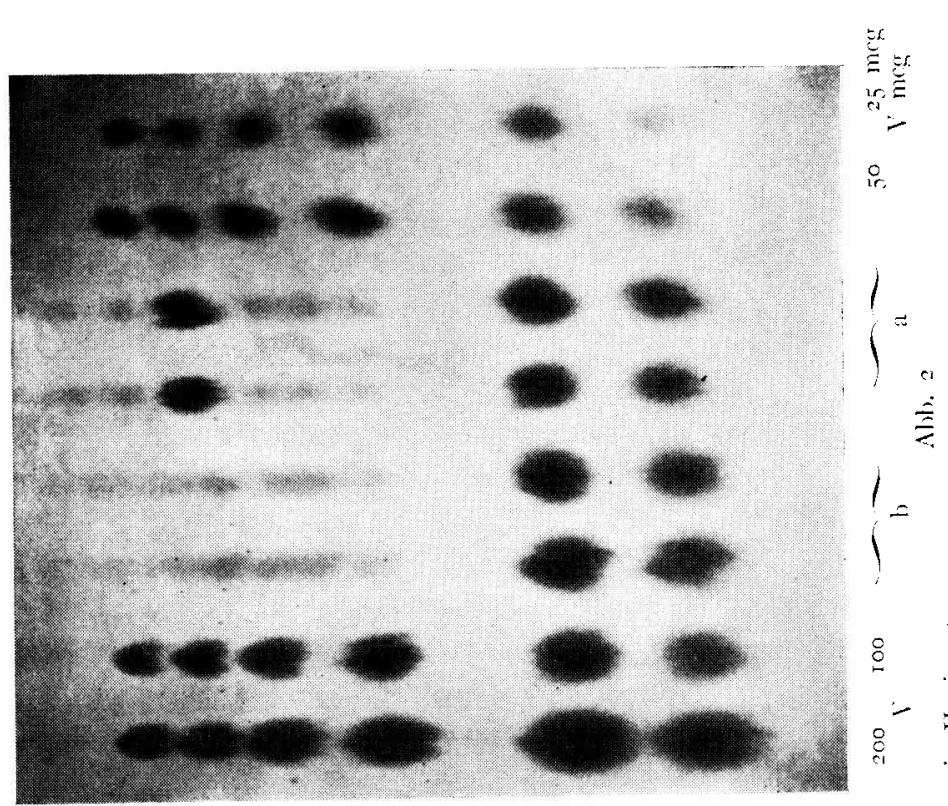

童㝘

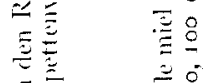

.

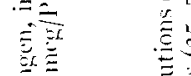

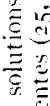

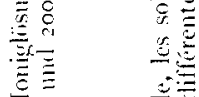

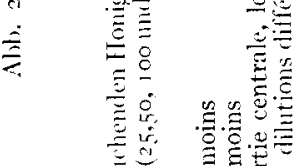

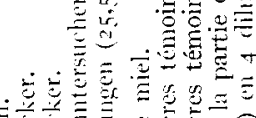

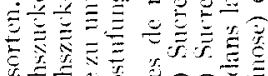

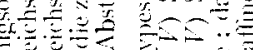

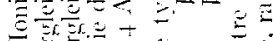
要要

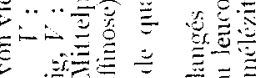

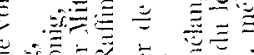

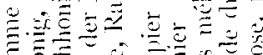

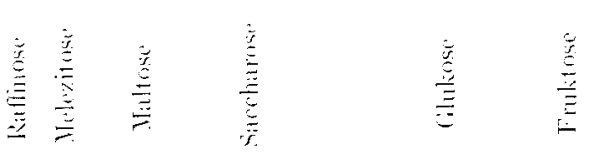

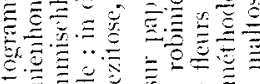

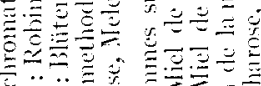

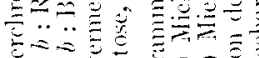

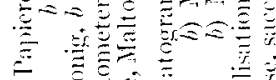

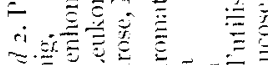
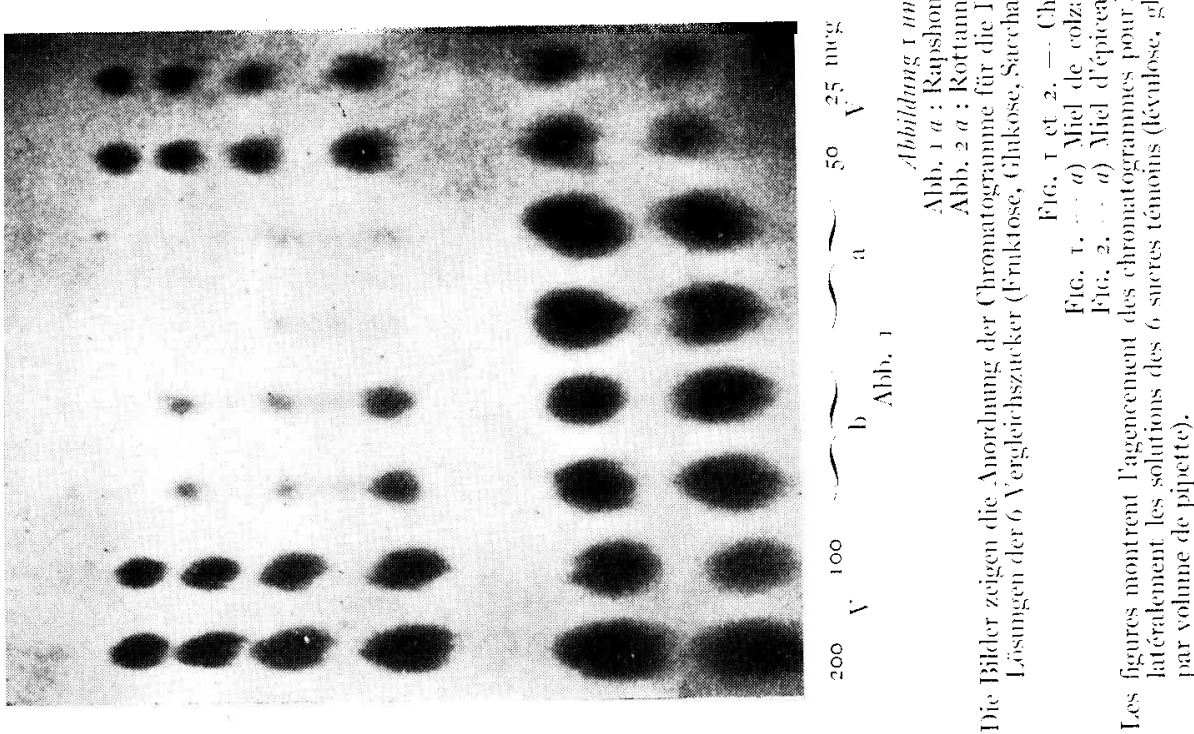
messbare Ilecke angedeutet sind; im Akazienhonig erscheinen ausser Fruktose und Glukose, ein deutlicher Saccharosenfleck und darüber 4 weitere Zuckerflecke, von welchen einer der Maltose entsprechen dürfte. Noch augenfälliger ist der Unterschied zwischen den in Abb. 2 dargestellten Chromatogrammen. Der Bliitenmischhonig führt neben liruktose und Glukose eine Kette von mindestens 6 schwachen Zuckerflecken, darunter Saccharose und Maltose ; im Rottannenhonig wird die Oligosaccharid-Kette durch einen starken Melezitosefleck unterbrochen und beherrscht. Diese Beobachtungen werden durch die von Austin, Goldschmidt und Burkert, White (I957) and White and Maher (I954) aus der Untersuchung europäischer und nordamerikanischer Naturhonige gewonnenen Resultate bestätigt. Sie lassen vermuten, dass das Zuckerbild des fertigen Honigs von den Zuckerarten und Fermenten der Rohstoffe beeinflusst wird, und dass demnach bei Honigen verschiedener botanischer Herkunft, mit charakteristischen Unterschieden im Zuckerbild zu rechnen ist. Es war weiter anzunehmen, dass solche, auf den Eigenschaften der Rohstoffe beruhende Unterschiede bei Honigen aus einseitiger 'Tracht von nur einer Pflanzenart (sog. Sortenhonigen) deutlicher zu Tage treten mïssen, als bei Mischhonigen, an deren Entstehung zahlreiche Pflanzenarten beteiligt sind. Solche, aus vorherrschender Tracht von nur einer Pflanzenart stammende Honige, sind mikroskopisch durch das zahlenmässige Vorherrschen einer Pollenform (I eitpollen) charakterisiert. Bei der Beurteilıng der botanischen Herkunft von Honigen muss jedoch der Unstand beriicksichtigt werden, dass je nach Bau und bliitenbiologischen Finrichtungen, bei den einzelner Pflanzenarten verschieden viel Pollenköner in die Iünheit Nektar gelangen. Die Prozentzahlen der Pollenauszählıng in Honigpräparat sind deshalb für die einzelnen Formen nicht gleichwertig and bedürfen gewisser Korrekturen. Ich habe versucht durch Ieststellung der absoluten Zah1 pflanzlicher Bestandteile pro Honigeinheit eine Vergleichsbasis für die richtige Beurteilung verschiedener Honigsorten zu schaffen. Fis zeigte sich dabei, dass neben einer grossen Gruppe von Honigsorten mit annähernd gleichem absolutem Gehalt pflanzlicher Bestandteile, extrem pollenreiche (z. B. Myosotis-nnd Castanea-Honige) und extrem pollenarme (z. B. Robinia-, Lavandula-, Salvia-und Tilia-Honige) vorkommen (Maurizio I949, I955, I958).

Es stellte sich nun die Irage, ob der Einfluss der Rohstoffe auf das endgültige Zuckerspektrum des Honigs stark genng ist, um sich innerhalb der einzelnen Honigsorten, parallel zum Pollenbild bemerkbar zu machen, d. h. ob das Zuckerspektrum des Honigs sur Unterstüzung der mikroskopischen Herkunftsbestimmung herangezogen werden kann.

Zur Abklärung der aufgeworfenen Iragen unternahm ich in den letzten Jahren papierchromatographische Untersuchungen an einem 
grösseren Material ron Blïten-Sorten und-Mischhonigen, nud soweit es nöglich war an den dazu gehörenden Nektarsorten. I) ie botanische Herkunft der antersuchten Honige wurden mit Hilfe der Pollenanalyse bestimmt. I)ie Charakterisienung des Zuckerspektrums geschah einerseits anhand qualitativer Chromatogramme (Zahl and Verteilung der Zuckerarte11), anderseits durch (quantitative chromatographische Bestimmung der drei Hauptzucker (liruktose, Glukose, saccharose) und das daraus berechnete Verhältnis zwischen Iiruktose und Glukose nnd zwischen Saccharose und der summe der Hexosen (Ir/G1; silir (il). Bei einer beschränkten Anzahl von Honigproben wurden ansserden Maltose und Oligosaccharide quantitativ bestimmt. In ganzen wurden Nektarproben von 32 l'flanzenarten, 330 Blüten-Misch-und-Sortenhonige ans 23 I,ändern und Io Proben von Zuckerfütterungshonigen verarbeitet.

Allen, die mir bei der Ausführung der vorliegenden Arbeit durch Zusendung ron Nektar-und Honigmaterial geholfen haben, sei hier der beste I)ank ausgesprochen, vor allem Herrn E. Barbier, Nice, Herrn und Iiran Cipolla, Bellinzona, Herm I)r. H. Duisberg, Brenlen, Herrn I)r. J. Eckert, Davis, Irau Dr. A. Fossel, Aigen, Herrn E. Kamo, Truro, Herm D). J. Lonieanx, Bures, Hersn. Dr. G. Pritsch, Hohenneundorf, Irau O. Rochat, Bex und Herrn, I)r. F. Ruttner, L,unz. Die technischen Arbeiten der Papierchromatographie führten lirl. $M$. Zuberbïhler and Iirl. $M$. Schmits, I,iebefeld aus, denen ich für die Mitarbeit bestens danke. Alle in der Arbeit verwendeten Photographien stammen von lirl. H. Kollmann, I,iebefeld.

\section{METHODIK}

\section{Nektar.}

Der Nektar wurde mit Kapillarpipetten aus Bliiten entnomnen and sofort auf Chromatographie-Papier gebracht. In der Regel wurden dazu in I'reien wachsende Pflanzen verwendet, die vor der Nektarentnahne $2+$ Stunden mit Gazebenteln vor Insektenbesuch geschützt waren. In einzelnen Fallen erfolgte die Nektarentnahme aus Bliiten ron abgeschnittenen in Iaboratorinm in Vasser eingestellten Zweigen (z. B. Eucalyptus, (astanea, Rhododendron). Bei Fagopurum sagittatum, Taraxacum officinale und Salix caprea wurde der Nektar durch zentrifugieren gewonnen, da er für (Blaskapillaren kanm z.1gänglich ist.

Der Gesantzuckergehalt des Nektars wurde vor den Auflegen auf

Papier mit einem Zciss-Abbe-Refraktometer genessen, und falls nötig

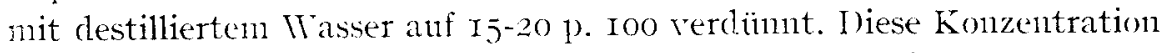
erwies sich als die geeignetste für die quantitative papierchromatographische Messmethode. 


\section{Honig.}

Die untersuchten Honige wurden vor dem Auftragen auf Chromatographiepapier in destilliertem Wasser gelöst und mit Hilfe des Refraktometers auf I5-20 p. Ioo Gesamtzucker eingestellt. Die Auswahl der Honigproben geschah auf Grund der pollenanalytischen Unterstuchung, wobei vor allem Blïten-Sortenhonige Berïcksichtigung fanden. Alle verarbeiteten Honige sind mikroskopisch untersucht worden, zum Teil wurden an ihnen quantitative Pollenanalysen unternommen.

\section{Papierchromatographische Verarbeitung.}

Alle Chromatogramme wurden auf Papier Whatman $\mathrm{r}$, bei Zimmertemperatur ausgeführt. Die Trennung erfolgte im absteigenden Verfahren mit dem n-Butanol-Essigsäure-Wasser-Gemisch, anfänglich im Verhältnis $4: I: 5$ später im Verhältnis $4: I: I$, das sich sehr gut bewährte. Die Durchlaufzeit betrug, je nach Jahreszeit und Raumtemperatur 2 I $/ 2$ bis 4 Tage. Die L,ösungen wurden mit geeichten Kapillarpipetten auf das Papier gebracht. Die Entwicklung erfolgte durch Bespritzung mit einer I p. Ioo I_ösung von p-Anisidin-Hydrochlorid in absolutem Alkohol. Un eine gleichmässige Durchdringung des Papiers mit dem Spritzmittel zu gewährleisten, was für die photometrische Messmethode wichtig ist, wurde die spritzung auf dem Hintergrund einer beleuchteten Milchglasscheibe vorgenommen (Linskens). Die lufttrockenen Chromatogramme wurden sodann in einem in I,iebefeld konstruierten elektrischen Heizofen (Manrizio I957) bei IIO-I20 C, 5-15 Minuten entwickelt.

Zur quantitativen Bestimmung der Zucker in den Chromatogrammen verwendete ich anfänglich die von Partridge und Westall, Flood, Hirst und Jones, Nelson und Somogyi beschriebenen Methoden. Danach werden die Randpartien des Chromatogramms entwickelt und die dazwischen liegende, nicht entwickelte Mittelpartie in Streifen geschnitten. Die darauf befindlichen Zucker werden im Rücklaufkühler eluiert, Fruktose und Glukose direkt, Saccharose nach Inversion kolorimetrisch bestimmt. Ich verwendete zur Inversion das Invertase Concentrate des British Drughouse I td., für die kolorimetrische Bestimnung das Beckmann Quarz-Spektrophotometer.

In den letzten drei Jahren ging ich dazu ïber die quantitative Bestimmung der Zucker in den Papierchromatogrammen mit dem photoelektrischen Leukometer auszuführen. Fs handelt sich dabei um eine direkte photometrische Messmethode, mit Hilfe einer im Messkörper (I,eukometer) eingebauten Photozelle (Selenphotoelement), die an ein Galvanometer (Multiflex-Galvanometer, Lange, Berlin) angeschlossen ist. Die Methode ist von Sulser zur quantitativen Papierchromatographie in 
der Lebensmittelchemie ausgearbeitet worden und hat sich auch in Arbeiten iiber Nektar and Honig bewährt. Sie ist, im Vergleich zur Eluierungsmethode zeitsparend und erlaubt in der gleichen Zeit und bei gleicher Sicherheit, ein wesentlich umfangreicheres Material zut verarbeiten. Fin auf breiter Basis angelegter Vergleich der beiden Methoden ist im Gange. Nach den bisherigen Beobachtungen scheinen die mit der Leukometermethode bestimmten Zuckermengen in allgemeinen etwas niedriger zu sein, als die durch Eluierung gewonnenen. Lis ist möglich, dass diese Unterschiede zunn Teil durch I'ehlerquellen der Eluiernngsnethode entstehen, indem zusätzliche, aus der Zellulose des Papiers stammende Zuckermengen mitbestinment werden (.McDonald).

Die Anordnung der Chromatogramme für die Leukometermethode ist aus den Abbildungen I and 2 ersichtlich. In den Randpartien werden Standard-I ösungen von I'ruktose, Glukose, Saccharose, Maltose, Melezitose und Raffinose aufgetragen, welche die Zucker in Mengen von 25, 50, Ioo, und $200 \mathrm{mcg}$, berechnet auf das Pipettenvolumen enthalten. In der Mittelpartie sind die geprüften Nektar-oder Honiglösungen aufgetragen. Nach der Lintwickling des ganzen Blattes werden die Flecke jeder Zuckerart mit dem I eukometer gemessen, wobei als Blindwert (zu1r Ausschaltung des Papierfarbwertes) cin freies Ield in der nächsten Umgebung des gemessenen \%uckerflecks gewählt wird. Un die Schwankungen zwischen den Finzelbestimnungen auf ein Mindestmass zu beschränken, wurden die geprïften I,östngen in je zwei Parallelpunkten auf die Chromatogramme gebracht, diese in zwei Wiederholungen geführt and jeder Zuckerfleck auf beiclen Papierseiten gemessen. Die endgültigen Resultate sind demnach Mittelwerte aus 8 Ablesungen an 4 Zuckerflecken. Die Nektaruntersuchungen wurden, soweit als möglich in mehreren Wiederholungen aus verschiedenen Probeentnahmen, die Honiguntersuchungen meist in zwei Wiederholungen mit beiden Bestimmungsmethoden ausgefuihrt.

Die Galvanoneterablesungen der Flecke der 4 Standardlösungen werden, separat für jedes Chromatogramm und jeden Zucker, auf halblogarithmischem Papier aufgetragen. Sie ergeben Eichkurven, auf welchen die Galvanometerwerte der Zuckerflecke in mcg pro Pipettenvolumen abgelesen werden. Daraus lassen sich die Zuckermengen in nng/ccm der geprïften I,ösung umrechnen (Einzelheiten der I,eukometerMethode s. Sulser).

Zur Festhaltung der qualitativen Iirgebnisse wurden die Chromatogramme photographiert. Die Resultate der quantitativen Zuckerbestimmungen wurden zunächst in $\mathrm{mg} / \mathrm{ccm}$ berechnet und dann in Prozenten ausgedriickt, wobei als roo p. too die Summe der Fruktose-, Glukose-und Saccharosewerte angenommen ist. In den nachfolgenden Tabellen ist jeweils der prozentuale Anteil der drei Hauptzucker, sowie 
ihr gegenseitiges Verhältnis angegeben (Fr ( 1 ; ; S Ir $\perp$ (il). 'labelle 8 enthä1t ausserdem die Bestimnnngsergebnisse für Maltose und löhermolekulare Zuckerarten*.

\section{ERGEBNISSE}

Wie weiter oben erwähnt wurde, besitzen Naturhonige inn allgemeinen ein ausgeglichenes Zuckerspektrun, das jecloch, je nach der Herkunft der daran beteiligten Rohstoffe gewisse charakteristische Abweichungen zeigen kann. Als (irundlage zur Beurteilung solcher, auf einseitige 'Tracht zurückgehender Abweichungen kann das Zttckerbild von Blüten-Mischhonigen dienen, die aus gleichzeitiger 'Tracht ron meloreren Pllanzenarten stanmen. Im folgenden werden deshalb zunächst die I ntersuchungsergebnisse ron Blüten-Mischhonigen und der an ihnen beteiligten Nektararten, und inn Anschluss daran die für sipezialtrachten charakteristischen Abweichungen besprochen.

\section{I. - Blïrn-IIisehhonignge.}

I) I Intersuchung der Bläten-Mischhonige umfasst $7+$ Honignoroben schweizerischer und ausländischer Herkunft, die ans Mischtracht von lirïljahrs-und Sommerphanzen stammen und keine Honigtaubestandeile enthalten. Als hauptsächliche Nektarspender sind claran beteiligt : Obstbämme (Pirus-und Prumus-Arten), Rubus-Arten, Taraxacum officinale Weber, Crucifereir, Lesculus Hippocastanam I.., Heradeam sphondylium $\mathrm{I}_{1}, 1 /$ yosotis sp). und I, eguminosen. Der Anteil der einzelnen Jurmen blicb in den Grenzen des Begleitpollant;

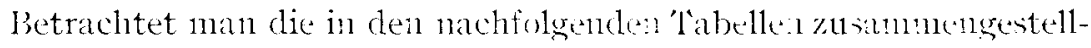
ten, und die ans der I,iteratur bekannt gewordenen Iirgebnisse der papierchromatographichen I'ntersuchung ron Noktar verschiedener Pflanzenarten, so fällt vor allen auf, in wie weiten firenzen clas Mengenrerhältnis der drei Hauptzucker schwankt. In manehen PHanzenfamilien zeigt das Zuckerbild des Nektars eine'n einheitlichen 'Iypus, in andern bestehen von Gattung zu c Gattung und von Art zu Art sehr crrosse linterschiede. So enthalt $z$. B. der Nektar aller bisher untersuchten Cruciferen fast ansschliesslich Hexosen, während bei den I eguminosen und I abiaten

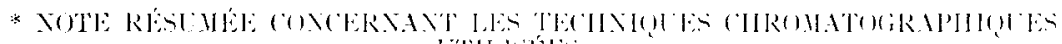
"lilinElis

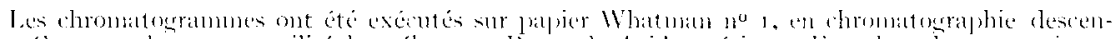

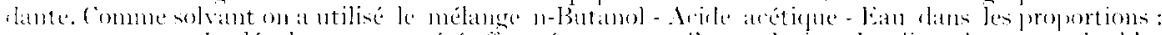

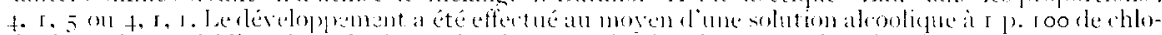

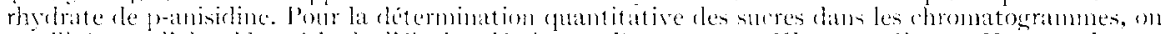

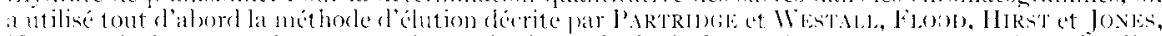

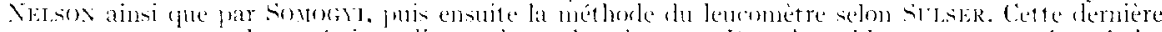

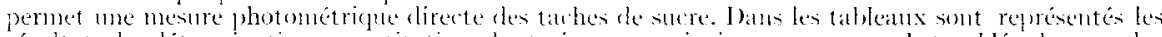

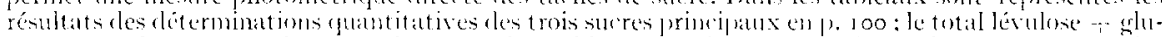

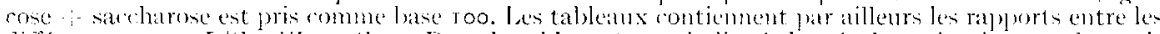

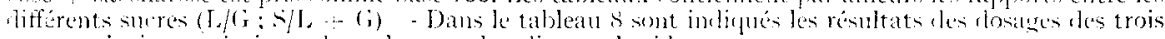

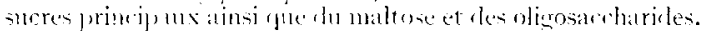


stets grössere Mengen Saccharose vorhanden sind; bei den Rosaceen sind innerhalb der einzelnen (rattungen beide 'Typen des Zuckerspektrums zu finden. Fbenso grossen schwankungen ist clas gegenseitige Verhältnis der beiden Hexosen tulterworfen (s. 'Tab. I, 3-7, 9). Iis war deshalb anzunehmen, dass in Mischhonigen, die aus gleichzeitiger 'Tracint von verschiedenen, in Bezug auf das Zuckerspektrum voneinander abweichenden Nektararten stammen, der Einfluss der Zuckerverhältnisse der Rohstoffe weitgehend ausgeschaltet ist.

\section{'TABEs.i: I. - Papierchromatographische Lintersuchung ion Vektar} rerschiedener Pflanzenarten und ron Blïtenmischlhonigen.

TABIfAY I. - Examen par chromatographie sur papior du nectur de différentes plantes et de miels de fleurs iariées.

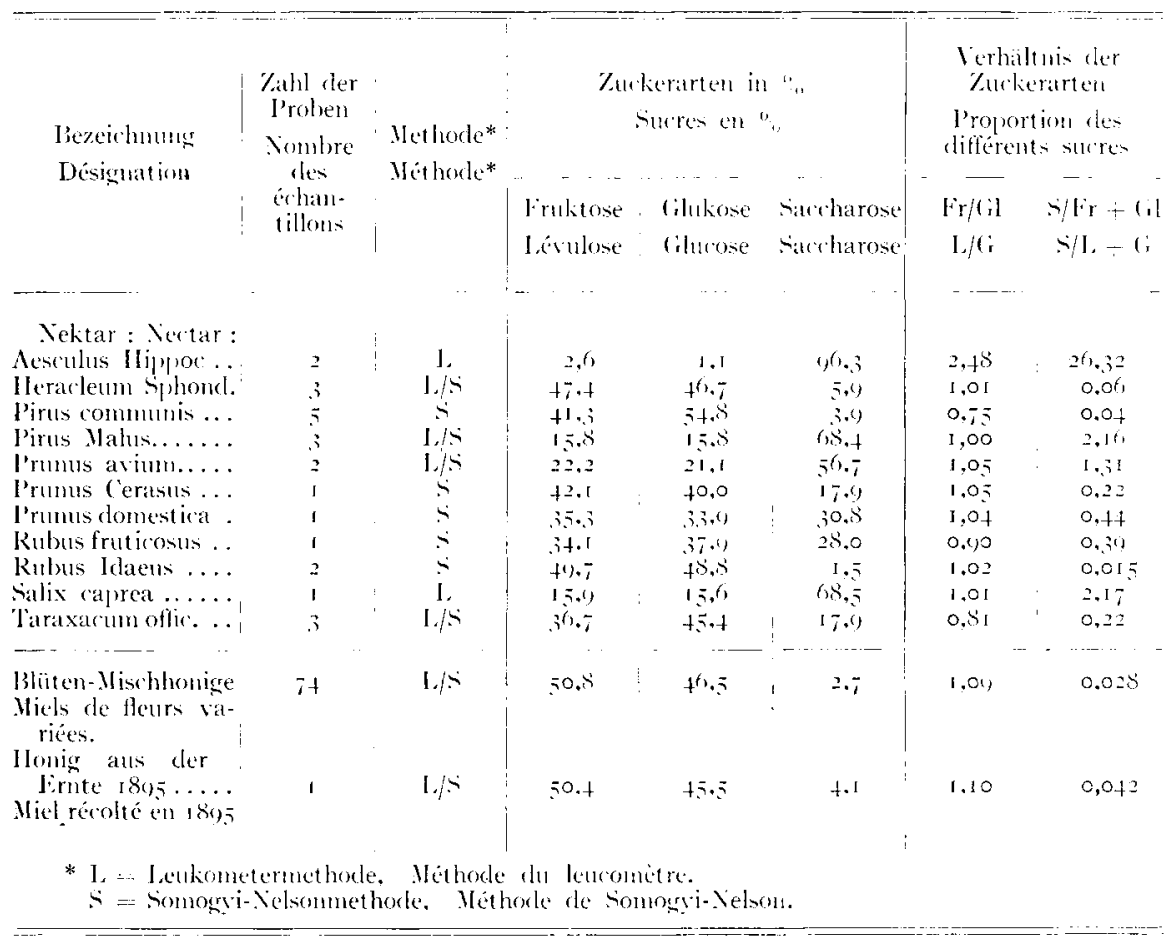

Die papierchromatographische Untersuchung der Blïten-Mischhonige bestätigt diese Annahme, denn ihr Zuckerbild ist durch einen annähernden ( Bleichgewichtszustand zwischen den beiden Hexosen (i. M. Irr G1 $=\mathrm{I}, 09$ ) und einen niedrigen Saccharosegehalt (i. M. S Fr $+(\mathbf{r} 1=0,028)$ gekennzeichnet ('Tab. I). Ausserdem sind in den Chronatogrammen der Mischhonige fast immer schwache I'lecke ron Maltose und Oligosacchariden zu finden. Sehr charakteristisch für das Zuckerbild der Blüten-Misch- 
honige, und des Blïtenhonigs in allgemeinen ist das Auftreten von: " Doppelffecken " in den Chromatogrammen. I)arunter verstehe ich Zuckerflecke mit annähernd gleichen $R_{p}$ - Vierten, die in Chromatogramm knapp untereinander lokalisiert sind. Ein solcher Doppelfleck fundet sich regelmässig auf der Höhe der Maltose und diirfte der Maltose und Isomaltose entsprechen; ein zweiter, ans 2 oder 3 I'lecken bestehender, liegt auf der Höhe der Melezitose und umfasst wahrscheinlich die 'Trisaccharide Erlose, Kestose und Melezitose (Abb. 2, 3, I 2, I.5 usw. Goldschmidt und Burkert, dort weitere I iteratur).

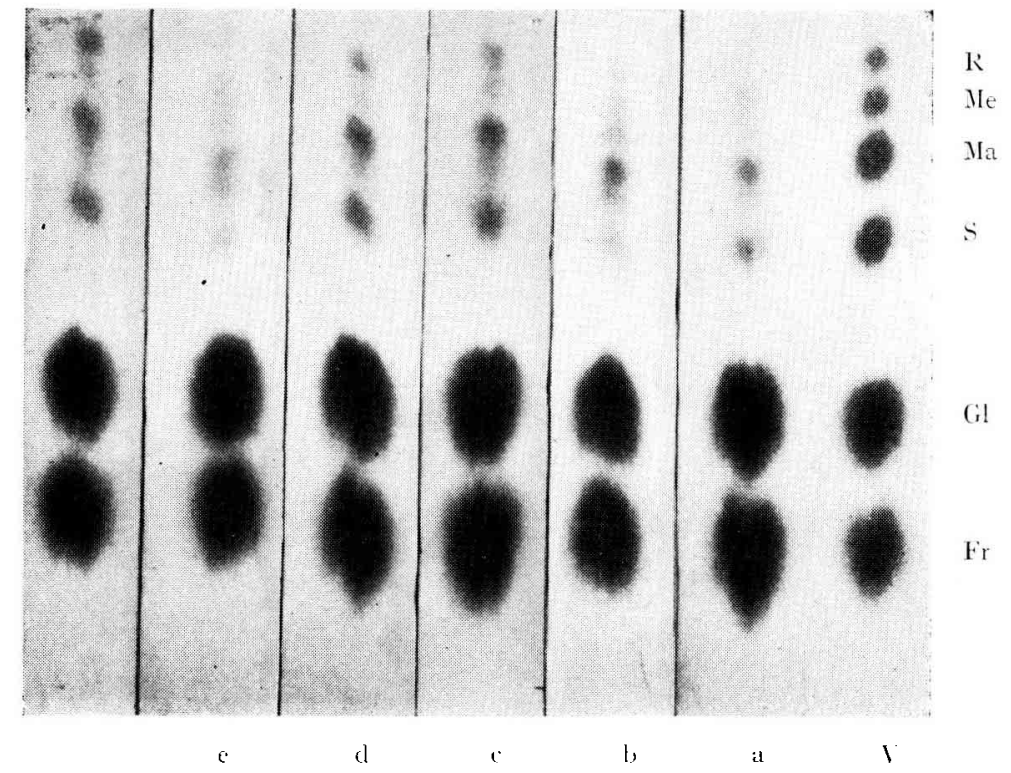

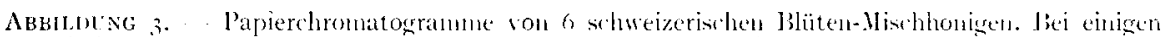
sind deutliche Doppelflerke siehtbar auf der Höhe der Maltose (Maltuse/ Somidtose) und der Melezitose (Erlose/hestose/Melezitone). I' : Verrleichszucker. a-f : Honige.

Fic. i. - Chromatogranmes de six miels suisses de fleurs melangées. (hey certains de res aniels, les laches doubles sont nettement visibles au niveau du maltose (maltose/isonaltose) et du mélé zitose (erlose/kestose/mélézitose). 1 : sucres témoins, a-f : miels.

I)ieses Zuckerbild ist ein Produkt aus dem Zusammenspiel nehrerer Faktoren. Iis kann als typisch für Blütenhonig gelten und als "Norm" für die Benrteilung von sortenhonigen dienen. Es wird einerseits durch die ursprïnglich in den Rohstoffen enthaltenen Zuckerarten and Fermente, anderseits durch die Invertasen der Bienensekrete, die währenc! des Reifungsprozesses in den Honig gelangen, beeinflusst. Auch das Alter des Honigs, d. h. die Einwirkungszeit der Invertasen spielt dabei eine gewisse Rolle.

Die Karbohydrasen der Biene, welche während der Reifung in den Honig gelangen stammen zur Hauptsache aus dem sekret der Pharynx- 
drüsen. Sie sind fähig die zusammengesetzten Zucker des Rohstoffs in einfache Zucherarten, unter gleichzeitiger Bildung von Oligosacchariden abzubauen. I) ursprïnglich vorhandene Saccharose wird dabei in kurzer Zeit hydrolysiert, wobei das endgültige Verhältnis zwischen den entstandenen Hexosen (Iiruktose 1nd (Glukose) annähernd I, oo beträgt (Maurizio I957, I959 und noch nicht publizierte quantitative Untersuchungen).

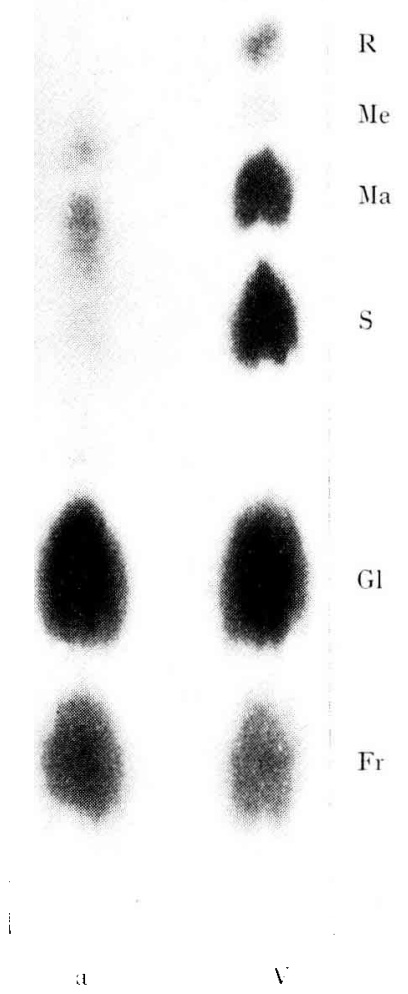

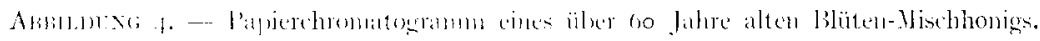

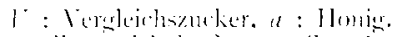

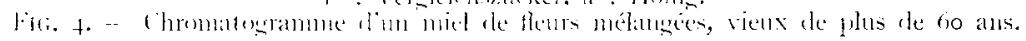
1 : sucter temoins a : nniel.

Interessant ist die I'rage, wieweit das Zuckerbild des Honigs von der Jagernngszeit abhängig ist. Ich hatte (iclegenheit diese Iirage an einem I895 geennteten, auf dem listrich eines alten Hauses gelagerten BlütenMischhonig zu prüfen. Als er nach rund bo Jahren zur Intersuchung kam, war dieser Honig zwar verlärbt, jedoch wnvergoren and in Geschmack völlig normal. Das Irgebnis der papierchromatographischen Untersuchung ist aus Abb. + und 'Tabelle I ersichtlich. I as Verhältnis zwischen Iiruktose und Glukose beträgt in diesem Honig $I, I 0$, der saccharosegehalt ent- 
spricht noch völlig demjenigen frischer l3lïtenhonige (S Fr $-(\mathrm{i} 1=0,042$, 'lab. I). I)er Honig zeigt ein typisches Zuckerbild, mit starken Ir ruktoseund Glukoseflecken, wnd schwachen liecken von saccharose, Maltose tund mehreren Oligosacchariden (Abb. 4). I)ieser Befund beweist, dass der saccharose-Abbau im Honig sehr langsan vor sich geht nund anch nach to Jahren noch nicht völig beendigt ist. Fis ist anzunehnen, dass die $\mathrm{Hy}$ (brolyse im Honig durch irgendwelche Taktoren (pH, hoher Zuckergehalt) gehenment wird and nie bis zum endgültigen Verschwinden der Saccharose finht. Iis kann darans der schluss gezogen werclen, dass das charakteristische Znckerbild des Honigs sehr stabil und ron der Iagerungszeit unabhängig ist. Es eignet sich deshalb als Basis zur Cnterscheidung ron Naturhonigen und Kunstprodukten, die unter der Bezeichn1111g "Kun1sthonig ", "lafelhonig "usw. auf den Markt kommen.

Die firage ob sog. "Zuckerfulterungshunige ", d. h. Produkte, die ans Zuckerbeifutterung in Bienenvolkern willurend der 'l'rachtzeit entstehen, anland der papierchromatographischet1 Entersuchung von reinen Naturhonigen unterschieden werden kïnnen, ist schon mehrfach cliskutiert worden. Nach Täufel und heiss sollen Zuckerfütterungshonige keine höhermolekularen \%ackerarten, sondern nur die drei Hauptzucker enthalten ; coldschmidt and Burke' fanden dagegen in Winterfutter aus einer Vorratswabe neben den drei Hanptznckern, noch Maltose, Isomaltose and Iirlose. Sie zichen darans den ichluss, dass Maltose, Isomaltose, lirlose, lextrantriose und f-chcosyl-dextrantriose als l'rodukte der 'Transglykosidierung in Bienenkörper entstehen, während saccharose, Kestose, Melezitose nud Raffinose von den Ijienen in den Rohstoffen ringetragen werden.

Meine Intersuchumgen unfassen einge experinentell gewonnene Zuckerfütterungshonige. Sie stammen ans Vorsuchen, in welchen Violker eines standes, die anf IVaigen standen, in der 'Trachtzeit täglich mit gleichviel, oder halb soviel zuckerwasser gefiutert wurden, wie sie wähend des 'ages an (rewicht zugenommen hatten (Finz-lheiten der Versuche Maurizo, r9f9). Solche, wahrend der l'rachtzeit ans teilweiser Zackerfütterung entstandene Honige entsprechen den wirklichen Verlacitnissen im Handel besser, als die in der I,iteratur erwähnten, ans reiner Zuckerfütterung oder aus Winterwaben stammenden Produkte, die kaum zum Verkauf gelangen.

I) Resultate neiner Lntersuchnng ron /uckerfütterungshonigen sind aus 'Tabelle II und Abb. 5 ersichtlich. Is geht darans hervor, dass das Zuckerspektrum der Zackerfütterungshonige völlig demjenigen normaler Wischhonige entspricht. Weder im Verluältnis zwischen liruktose und (ilukose, noch im saccharosegehalt, oder den Vorkommen von Oligosacchariden ist zwischen den normalen Vergleichshonigen und den Zuckerfütterungshonigen ein fassbarer Vinterschied festzustellen. Ifeider bietet 


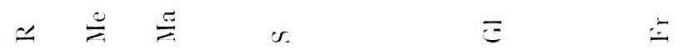
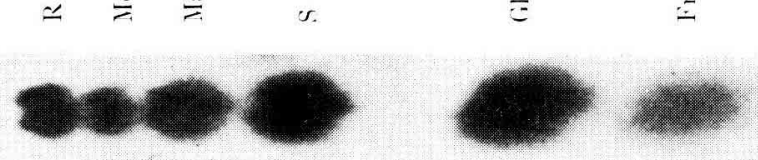

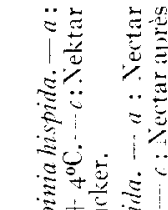

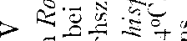
다. $\frac{\mathrm{c}}{2}=$

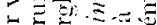

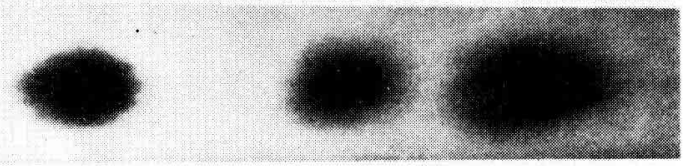

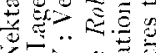

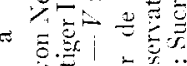

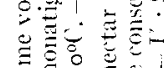

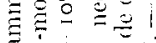

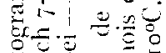

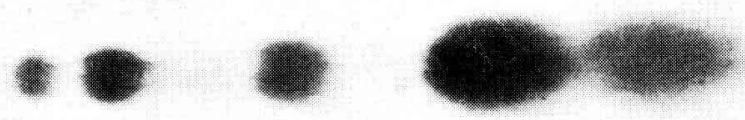

○

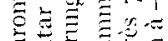

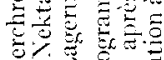

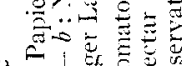

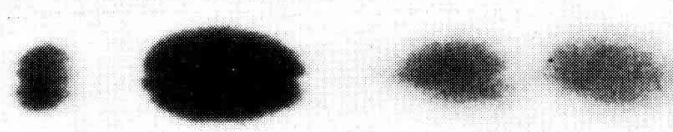

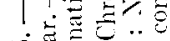
o.

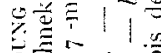

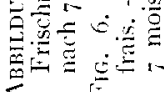
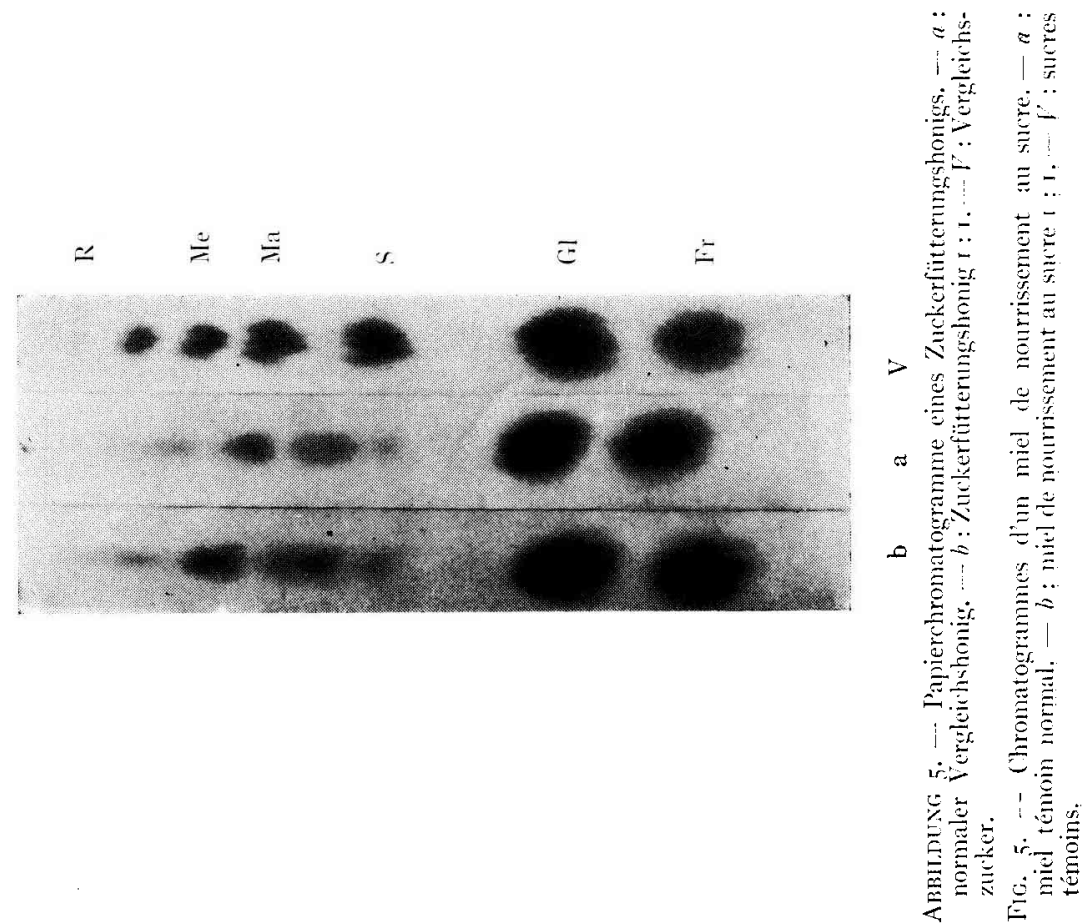
demnach die Papierchromatographie, ähnlich wie die makrochenische Analyse keine sicheren (irundlagen zum Nachweis von Zuckerfütterung im Honig.

$$
\begin{aligned}
& \text { TABEILE II. - Papierchromatographische Untersuchung } \\
& \text { ion Zuckerfutterungshonigen. } \\
& \text { TABLEAC II. - Examen par chromatographie sur papier } \\
& \text { de miels de nourrissement au sucre. }
\end{aligned}
$$

\begin{tabular}{|c|c|c|c|c|c|c|c|}
\hline \multirow{2}{*}{$\begin{array}{l}\text { Bezcichnung } \\
\text { Désignation }\end{array}$} & \multirow{2}{*}{$\begin{array}{l}\text { Yahl der } \\
\text { Proben } \\
\text { Yombre } \\
\text { des } \\
\text { echan- } \\
\text { tillons }\end{array}$} & \multirow{2}{*}{$\begin{array}{l}\text { Wethode } \\
\text { Wéthode }\end{array}$} & \multicolumn{3}{|c|}{$\begin{array}{l}\text { Zu kerarten in } \\
\text { sucres en of }\end{array}$} & \multicolumn{2}{|c|}{$\begin{array}{l}\text { Verhaltnis der } \\
\text { Zuckerarten } \\
\text { l'roportion des } \\
\text { différents sucres }\end{array}$} \\
\hline & & & $\begin{array}{l}\text { Fruktose } \\
\text { I.ciulose }\end{array}$ & $\begin{array}{l}\text { Gilukose } \\
\text { Glucose }\end{array}$ & $\begin{array}{l}\text { Sacharose } \\
\text { Sacharose }\end{array}$ & $\begin{array}{l}\text { fir/gil } \\
\text { I.fo }\end{array}$ & $\begin{array}{l}\text { S/Fr+Cil } \\
\text { S/I + C }\end{array}$ \\
\hline $\begin{array}{l}\text { Kontrolle (Verglei- } \\
\text { chsvölker ohne } \\
\text { Zuckerfütt ....... } \\
\text { Témoin (colonies té- } \\
\text { moins sans nour- } \\
\text { rissement aul su- } \\
\text { (re). } \\
\text { Zuckerbeifüttcrmur }\end{array}$ & 4 & IS & 55,2 & $+2,8$ & 2,0 & $\mathrm{~J}, 29$ & 0,02 \\
\hline 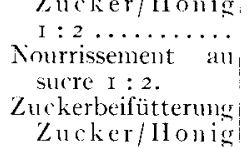 & 3 & L/S & 52,9 & $+.3 \cdot 4$ & 3,7 & 1,22 & $0,0,38$ \\
\hline $\begin{array}{l}\text { I: } 1 . \ldots . \ldots \ldots \\
\text { Nourrissement ant } \\
\text { sucre } I: 1 .\end{array}$ & 2 & $L / S$ & 52,1 & $+3,4$ &,+ 5 & $\mathrm{I}, 20$ & $0,0+7$ \\
\hline
\end{tabular}

\section{‥ - Bliiten-Sortenhonige.}

\section{Leguminosen.}

Die Leguminosen gehören in der ganzen Welt zu den wichtigsten Trachtpflanzen, die bestimmend sind für das Zustandekommen der Honigernte. In Mittel-und Nordeuropa and in Nordamerika stehen Kleearten im Vordergrund (Trifolium repens $\mathrm{I}_{1}$., Tr. hybridum $\mathrm{I}_{1 .}, T r$. pratense I..) ; in Mittel-, Süd- und Südosteuropa spielen Esparsette (Onobrychis viciifolia Scop.) und Robinie (Robinia pseudacacia I.) eine wichtige Rolle. I,uzernehonige (Medicago sativa I..) sind in Europa selten, sie kommen vor allem in gewissen Gegenden der Vereinigten Staaten und Kanadas zur Eirnte. Als Spezialtrachten sind zu erwähnen : Hornklee (Lotus corniculatus I.) in europäischen Berggebieten, Hahnenkamm (Hedysarum coronarim I..) in Xittelneerraun, Steinkleearten (Melilo- 
tus albus Desr., M. officinalis (I,. Lam.) in Nordamerika und die Sinnpflanze (Mimosa pudica I.) in subtropischen Gebieten.

Ich hatte Gelegenheit eine Anzahl von Robinien-, Iisparsette-, I ruzerne-, Weiss-nnd Rotklee-Sortenhonigen zu verarbeiten. Die Resultate sind in den Abb. 6-Io und Tabelle III zusammengestellt.

\section{Robinienhonige.}

I)ie Robinia-Arten gehören zu den an besten bearbeiteten Bienentrachtpflanzen. Is liegen heute eingehende Tntersuchungen über den Phloensaft, den Nektar und den Honig vor.

I)er Phloemsaft von Robinia psendacacia enthält als einzigen Zucker, Saccharose (1'arker, ITanner, Ziegler, Zimmermann I957). Im frisch gewonnenen Nektar herrscht sowohl bei Robinia pseudacacia, wie bei Robinia hispida saccharose mit über 50 p. roo vor ('Tab. III, Abb. 6 a). Oligosaccharide sind nicht vorhanden; nuter den Spaltprodukten ist ca 3,5 mal mehr liruktose als Glukose zu finden ('Tab. III). Wird cer Nektar in zugeschmolzenen (rlaskapillaren gelagert und in gewissen Zeitabständen auf Papier gebracht, so lässt sich der Saccharoseabban im Chromatogramme verfolgen. Nach Zimmermann (I954) nimmt der liruktosegehalt in gelagerten Rebinia-Nektar während der ersten 30 'Tage schneller zu, als der (ilukosegehalt. Nach meinen Versuchen gleicht sich bei längerer Iagerung im Külllschrank das Verhältnis zwischen I rrulstose und Glukose allmählich aus, wobei dit I agermugstemperatur eine wichtige Rolle spielt. So fand sich z. B. in Nektar von Robinia hispida nach 7monatiger Iagerung bei $-4^{\circ} \mathrm{C}$ annähemel gleich viel Iiruktose, wic

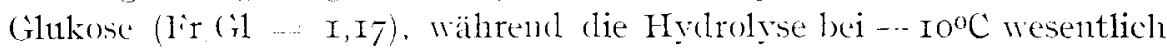
langsaner vor sich ging, so dass nach dicser Zeit der saccharosegehalt noch fast anverändert war und das Irnktose Glukose-Terhältnis noch 2,38 betrug ('Tab. III). In den Chromatogrammen des gelagerten Nektars erschicont11 neben saccharose, liruktose und Glukose deutliche Iilecke von mindestens + Oligosiccharilen, die in frischen Nektar fehlen (Ab). $6 \mathrm{~b}, c)$.

Ihas chromatographische Bild einseitiger Robinienhomige zeigt mehr oder weniger deutliche Saccharose-nund Iraltoseflecke und $3-4$ rlecke ron Oligosacchariden (Abb). 7). Der saccharosegehalt ist in frisch geernteten Honigen wesentlich hölner, als in längere Zeit hindurch gelagerten. Zwei Honigproben ants der Ernte 1958 enthielten 9,6 and 10,5 p. Ioo Saccharose und hatten ein Verhältniss s Iir + (\$1 von o, I I tund o, I2 (das Chromatogramm einer dieser Proben ist in Abb. I dargestellt). In Robinienhonigen aus früheren Jahren betrug der Saccharoseanteil 2-6 p. I00, i. II. 4,2 p. Ioo thnd das Verhältnis si Iir $\div$ ( i1 $=0,02-0,06$, i. MI. 0.045 ('lab. III). 
Den Hauptanteil bilden firuktose nnd Glukose, wobei in den Chromatogrammen das mengenmässige Vorherrschen von Firuktose schon von Auge zu erkennen ist. Nach der quantitativen Analyse enthalten einseitige Robinienhonige ungefähr anderdhalb mal mehr I'ruktose als Glukose (Ir/Gl i. M. I,6, Tab. III). Der für Kobinia-Nektar charakteristische hohe Fruktosegehalt wirkt sich demnach noch in Honig aus. Dieser İigenschaft verdankt der Robinienhonig seine Konsistenz. Eeinseitige Robinienhonige bleiben sehr lange flüssig und beginnen erst nach mehreren Jahren zu kristallisieren.

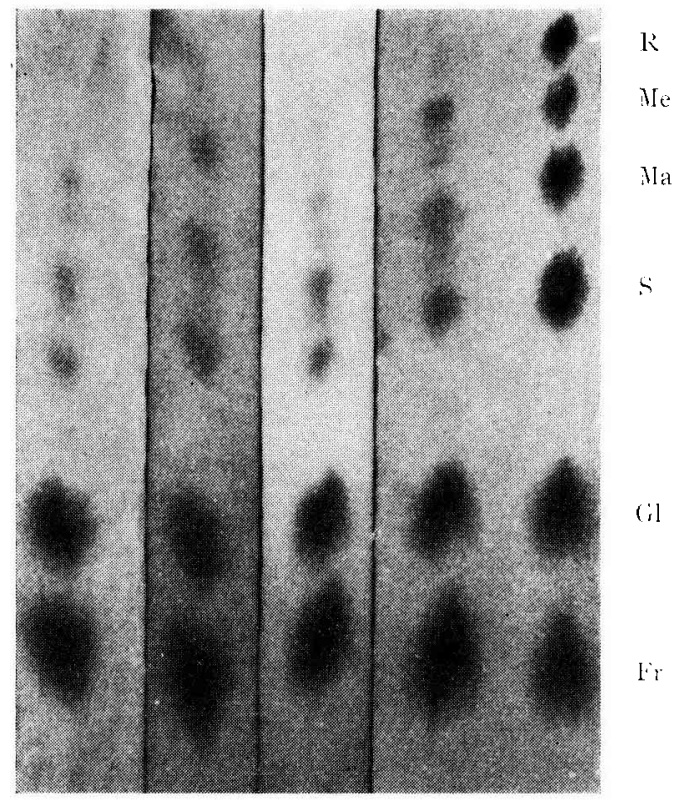

1

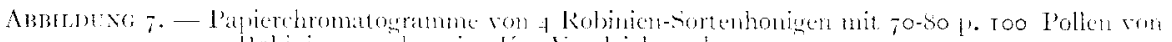

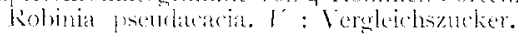

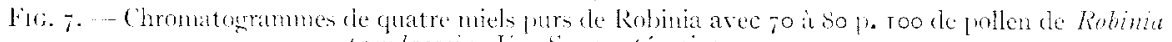

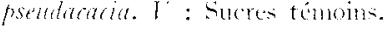

Werden die untersuchten Honige nach dem prozentualen Genhalt an Robinia-Pollen unterteilt, so sind zwischen den einzelnen Gruppen keine nemnenswerten Cnterschiede des Zuckerspektrums festzustellen. In Honigen mit einem Anteil von 70-80 p. I00, und von 50-70 p. Ioo Robinia-Pollen beträgt das Verhältnis Iiruktose Glukose $\mathrm{I}, 59$, resp. I,63; in Proben, die Robinia als Begleitpollen fithren (30-44 p. IOO) beträgt dieses Verhältnis I,7 I ('T'ab. III). Die Lnterschiede zwischen den drei Gruppen sind so gering, dass man von standpunkt der Znckerverhältnisse schon Honige mit einem Robinia-Begleitpollen als blütenreine Robinienhonige ansprechen kann. Diese Beobachtung stimmt mit den Befunden 


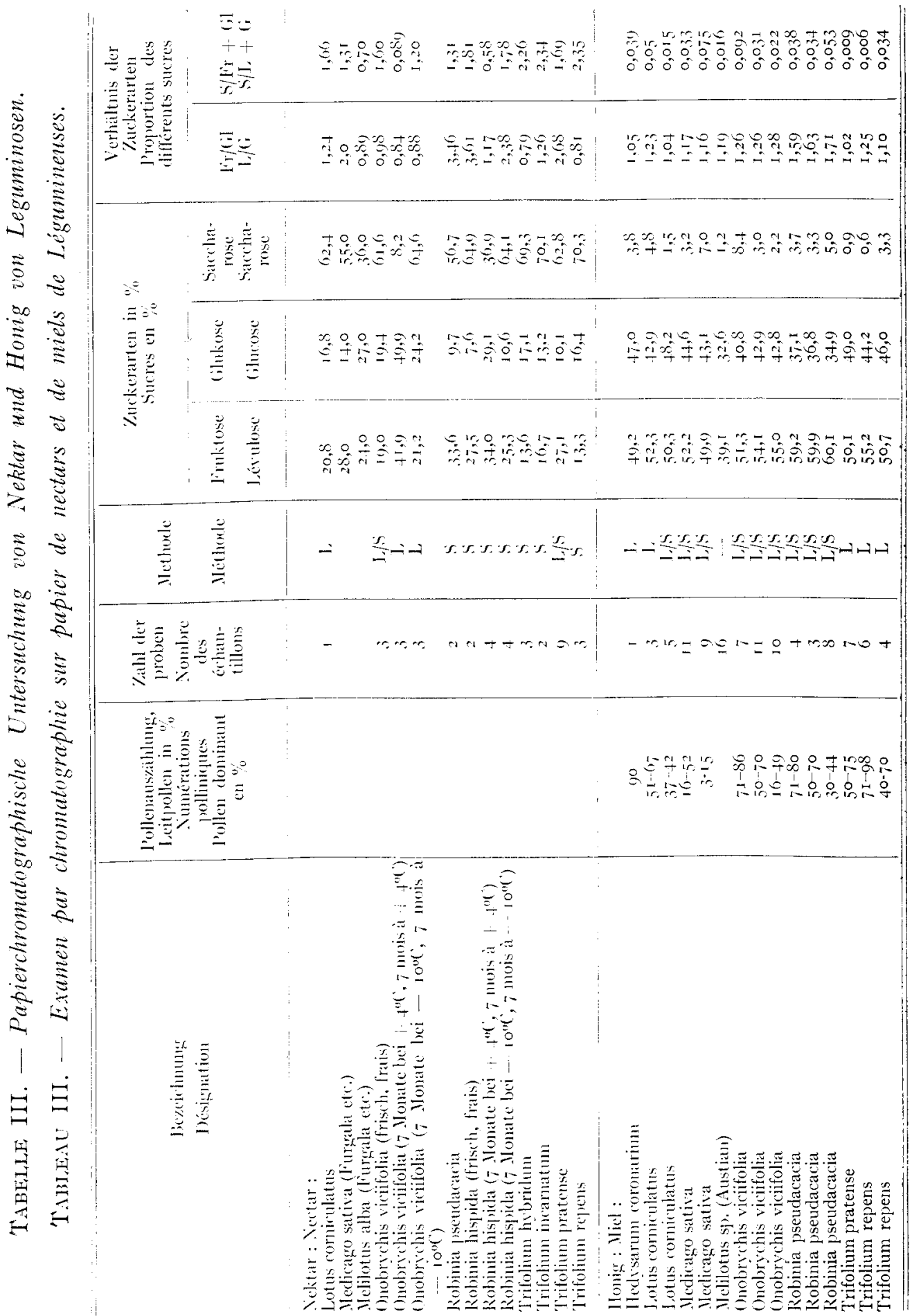


der quantitativen Pollenanalyse iiberein, wonach ein Honig schon als blütenrein zu betrachten ist, wenn er $40 \mathrm{p}$. Ioo Robinia-Pollen im mikroskopischen Bild enthält (.Maurizio I949, I958). Das Beispiel des Robinienhonigs zeigt, dass das Zuckerspektrum des reifen Honigs in gewissen Fällen von den Nektarfermenten beeinflusst wird, und dass die papierchromatographische Untersuchung, in Kombination mit der Pollenana1yse, als Hilfsmittel zur Beurteilung der botanische Herkunft des Honigs beigezogen werden kann.

\section{Esparsettehonige.}

Der frisch gewonnene Nektar von Onobrychis viciifolia enthält praktisch nur drei Zuckerarten, unter welchen saccharose mit ca 6o p. Ioo

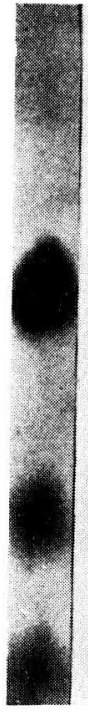

e

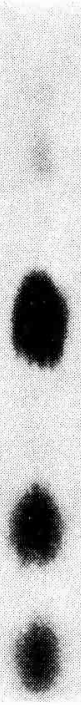

1

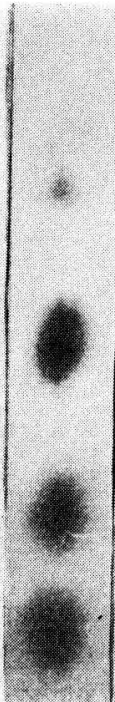

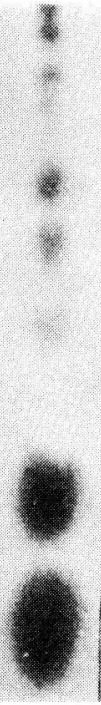

b)

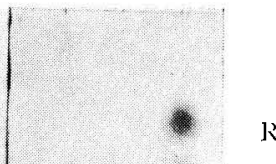

$\mathrm{Ne}$

Mit

$S$
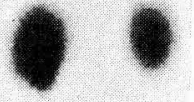

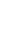

(il

Fr

V

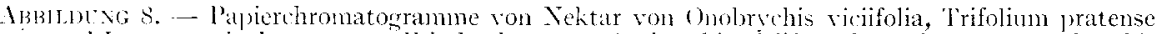
und Iotus cormiculatus. - $a$ : Fischnektar von Gnobrychis viciif. - - $b$ : Nektar von Onobrvehis vicif. nach 7 -monatiger Lascerung bei $+f^{\circ} \mathrm{C}$ - $c$ : Vektar von Onobrychis viciif, nach 7 -monatiger Layerng bei - $10^{\circ} \mathrm{C}-d$ : I'rischnektar von 'Trifolimn pratense. - - $e$ : Frischnelitar von Lotus comiculatus. - $V$ : Verglejchszucker.

Flc. s. - Chromatogrammes de nectar donobrychis inciifolia, Trifolium pratense et lotus cormiculalus. - $a$ : Nectar frais d'Onobrychis vicilfolia. - b : Nectar d'Onobrychis aicilfolia a!rè 7 mois

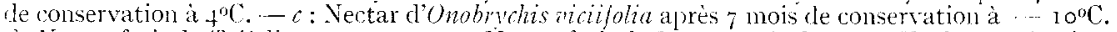

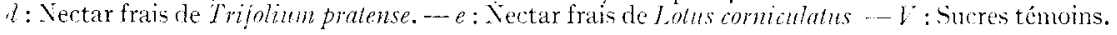

vorherrscht $(\mathrm{S} / \mathrm{Fr}+\mathrm{G} 1=\mathrm{I}, 60)$. In Chromatogramm erscheinen ausserdem noch zwei knapp sichtbare Iilecke, die Zuckern mit niedrigen $\mathrm{R}_{\mathrm{r}}$ Werten entsprechen (Abb. $8 a$ ). Fruktose und Glukose treten im frischen Onobrychis-Nektar, im Gegensatz zum Nektar der Robinia-Arten in annähernd gleichen Mengen auf (Fr/G1 = 0,98, Tab. I). Wird der Nektar 
im Kühlschrank gelagert, so erscheinen im Chromatogramm zahlreiche Oligosaccharidflecke, die bis zum Startpunkt reichen (Abb. 8 b). Der Glukosegehalt scheint während der Lagerung schneller zu steigen als der Fruktosegehalt ( $\mathrm{Ir} / \mathrm{G} 1$ nach 7 Monaten $=0,84$ und 0,88 , Tab. 3). Auch hier wird die Hydrolyse durch niedrige Temperatur stark verlangsamt. So enthielt der bei $+4^{\circ} \mathrm{C}$ gelagerte Nektar nach 7 Monaten nur noch 8 p. IOo Saccharose während der Saccharosegehalt des bei $-10^{\circ} \mathrm{C}$ gehaltenen Nektars noch fast unverändert war ('Tab. III, Abb. 8c).

In Chromatogrammen von Esparsettehonigen erscheinen regel-

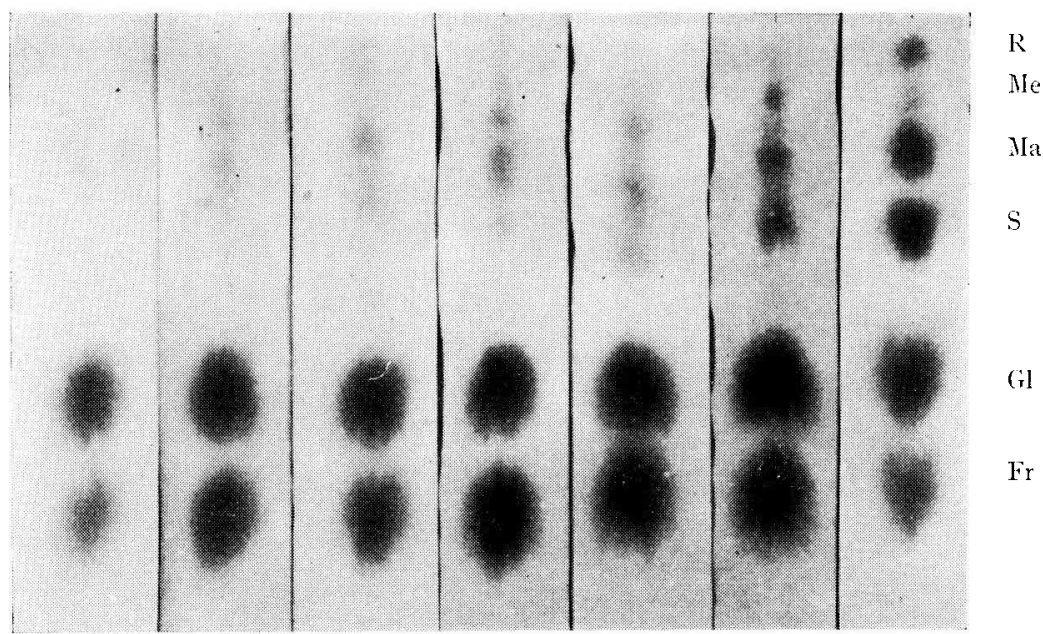

$\checkmark$

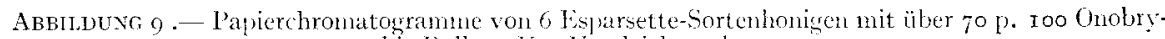
chis-Pollen. $\mathrm{I}$ : Vergleichszucker.

Fig. 9. - Chronatogranmes de six miels purs de sainfoin avec phus de $70 \%$. 100 de pollen de sainfoin. $V$ : Silcres témoins.

mässig neben Iiruktose und Glukose, mehrere Zuckerflecke, welche der Saccharose, der Maltose und Oligosacchariden entsprechen (Abb. 9).

Die 28 untersuchten Esparsettehonige wurden nach dem Gehalt an Onobrychis-Pollen in drei Gruppen eingeteilt. Zwischen diesen Gruppen sind in Bezug auf den I'ruktose-und Glukosegehalt keine Unterschiede vorhanden. Dagegen lässt sich bei den Honigen, im Vergleich zum Onobrychis-Nektar eine Zunahme von Fruktose feststellen ( $\mathrm{Fr} / \mathrm{Gl}$ im Nektar $=0,98$, im Honig $=1,26-1,28$, Tab. III). Die Tendenz zur Iruktose-Anreicherung bei Honigen, deren Rohstoff mehr Glukose als Fruktose enthält, dürfte auf einer Transglt1kosidierung durch die Bieneninvertasen beruhen.

Eine gewisse Abstufung zwischen den drei Honiggruppen lässt der Saccharosegehalt erkennen. Bei extrem einseitigen Esparsettehonigen 
betrïgt der Saccharoseanteil i. MI. 8 p. IOO (S Ir $+(\mathrm{il}=0,09)$, in Honigen mit geringeren Onobrychispollen-( Sehalt sinkt er anf 2-31). IOO (s I r + G1 $=0,022-0,03$ I, Tab. III). Nur Iisparsettehonige mit einem sehr hohen Anteil an Onobrychis-1'ollen (ïber 70 p. Ioo) scheinen demnach ein charakteristisches Zuckerspektrum zu besitzen, alle übrigen verhalten sich wie Bliiten-Mischhonige. I iese Feststellung ist insofurn interessant als ein Teil der Onobrychis-Honige sich in der quantitativen P'ollenanalyse als ziemlich pollenarm erwiesen hat, so dass der Vorschlag gemacht wurde, Esparsettehonige als bliitenrein zu betrachten, wenn sie ca fo p. Ioo Onobrychis-Pollen enthalten (.Manrisio r958).

\section{Kleehonige.}

Der frisch gewonnene Nektar von Trifolium repens, Tr. hybridum, $T r$. pratense und Tr. incarnatum enthält in der Regel nur clrei Zuckerarten, Fruktose, (ilukose und Saccharose. Bei allen vier untersuchten Kleearten herrscht im Chromatogramm des Nektars Saccharose mit 6o-7o p. Ioo ror. Unterschiede sind dagegen vorlanden in Bezug anf len Anteil I'ruktose und Glukose und die Bildung von Oligosacchariden. Während nach meinen Beobachtungen und den Befunden von Furgala und Mitarb. der Nektar von Trifolium repens und Tr. hybridum stets mehr bilukose als Irruktose enthält (Iir $(\mathrm{B} 1-0,79-0,8)^{\circ}$ ), herrscht im Rotklee-1nd Inkarnatklee-Nektar, I'ruktose vor (1'r (11 - I,27-2,68, Tab). III). Ausserclem muss Rotkleencktar eine wirksancre Invertase besitzen, dem1n es kommut öfters vor, dass in Nektàr, der nach 24-stündiger Abdeckung mit (razebeuteln gewonn1en wurcle, die saccharosehyclrolyse schon in vollem (jange ist and in Chromatogranm neben den drei Hanptzuckern eine ganze Anzahl von Oligosaccharicen erscheint (Abb). $8 d$ ). Bei Teiss-und Bastardkleenelitar labe ich diese lirscheinung bisher nie beobachtet.

In Klee-Sorlenhonigen sind diese Interschiede weitgehend ausgeglichen. Sowoh1 Weiss-wie Rotkleehonige enthalten knap1 mehr liruktose a1s crukose (I:r (51 = I,02-I,25, 'Tah. III); (ler Saccharosegehalt ist in beiden stark reeluziert $(S / \mathrm{Tr}+(\mathrm{i} 1=0,006-0,009$, 'l'ab. III. Abh. Io $a, b)$. Nur Weisskleehonige mit einem unter 70 1). Ioo liegenden Anteil von Trifolium-repens-Pollen besitzen einen höheren saccharosegehalt (s Iit

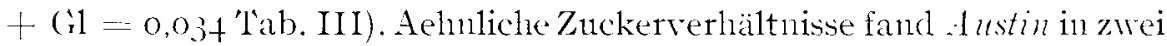
einseitigen Bastardkleehonigen. l)iese Befunde neisen auf das Vorhandensein einer Saccharase hin, die ans dem Yektar stammend, wirksam genug ist, un sich noch im Honig bemerkbar zu machen. Sie bestätigen die oben angeführte Beobachtung, wonach die Saccharose-Hydrolyse im Rotkleenektar sehr früh einsetzt und schon in der Blïte zur Bildung ron Oligosacchariden führt. I) Ke Kleehonige sind dennach durch ein mengenmässiges (ileichgewicht zwischen liruktose und Glukose und einen geringen saccharosegehalt gekennzeichnet. 


\section{Luzernehonige.}

Im Nektar von Medicagosatial besteht ungefähr die Hälfte des Zuckers aus Saccharose, der Rest entfällt zur Hauptsache auf liruktose, während Glukose und Maltose einen sehr geringen Anteil haben ('Tab. III, Angaben nach Furgala und Mitarh.).

Honige mit .Medicago-I.eitpollen sind verhältnismälssig selten. In luropa kommen sie kaum vor, und auch in den Vereinigten Staten and Kanada führen die als "alfalfa " bezeichneten Honige, I, nzerne meist

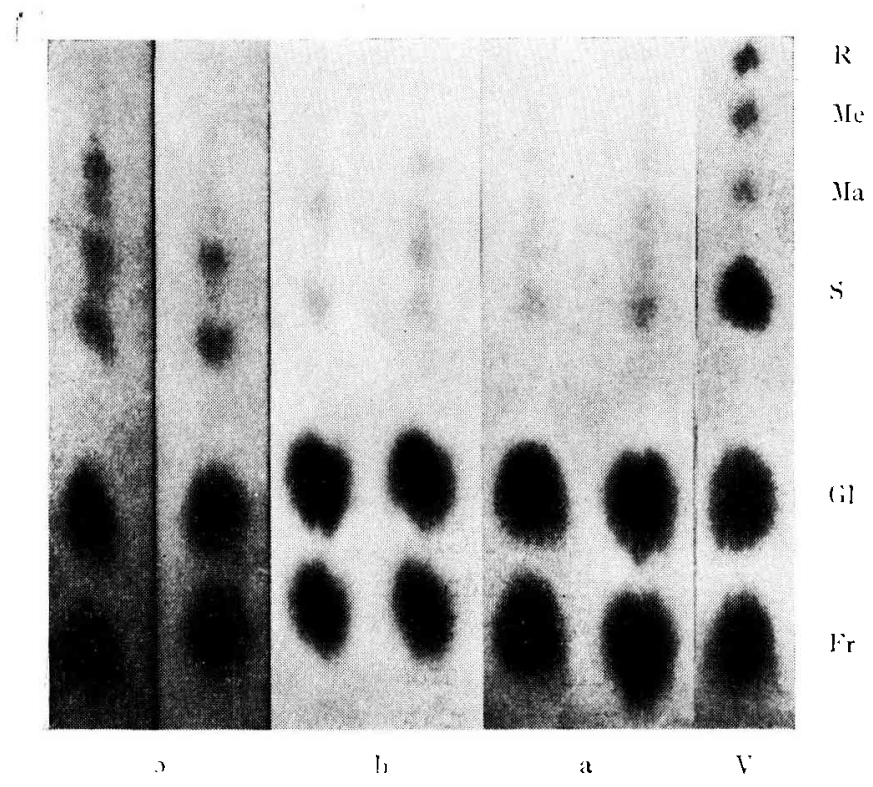

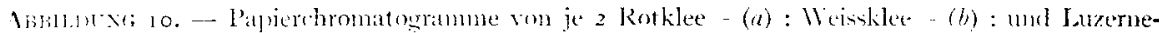
Itonigen. - (c) : $l^{2}:$ Vergleichsalcker.

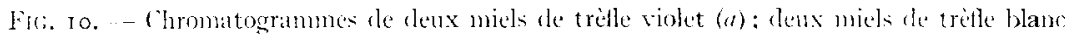
(b) et reux miels de luzerne (c). $l$ : surres timoins.

nur als Begleit-oder Einzelpollen. Unter den 20 von mir untersuchten, als Luzernehonig deklarierten Proben fand sich nur eine mit einem echten Medicago-I,eitpollen (52 p. IOo), in den übrigen war Medicago mit 336 p. roo vertreten.

Das Zuckerbild dieser Honige zeigte keine charakteristischen Merkmale. Das Verhältnis zwischen Iruktose und Glukose war mit I, I6-I, I7 gut ausgeglichen, der saccharosegehalt meist ziemlich hoch (S/Ir + G1 $\therefore=0,033-0,075$, 'Tab. III Abb. Io c). In der Regel waren in den Chronatogrammen Filecke von Maltose und $2-4$ Oligosacchariden vorhanden. Hine Enterteilung der untersuchten Proben nach dem Gehalt an I azernepollen zeitigte keine Interschiede in Zuckerspektrum zwischen den beiden 
Gruppen ('Iab. III). Austin fand in 7 kanadischen, als Alfalfahonige bezeichneten Proben ein Irruktose/Ginkose-Verhältnis das zwischen I,oI und I,I8 liegt und verhältnismässig niedrige Saccharosewerte (Saccharose/ Irruktose + Glukose i. M. 0,02 I). Diese Ausgeglichenheit des Zuckerbildes kann verschieden gedeutet werden. Entweder ist dieses Zuckerspektrum. charakteristisch für I,uzernehonige, wobei schon ein geringer Anteil Medicago-Pollen einem hohen Nektar-Anteil dieser Pflanze entspricht, oder sind die untersuchten Proben, im Sime der Pollenauszählung als Mischhonige zu betrachten, was ihr uncharakteristisches Zuckerbild erklären wïrde.

\section{Hornklee-, Steinklee - und Hahnenkammhonige.}

Ueber die Zuckerverteilung im Nektar von Hedysarmm coronarium (Sulla) ist meines Wissens bisher nichts bekannt ; die von mir verarbeitete Probe von Hornkleenektar enthielt fast doppelt so viel saccharose als Hexosen, und mehr Firuktose als Glukose ( $\mathrm{Fr} / \mathrm{Gr}=\mathrm{I}, 24 ; \mathrm{S} / \mathrm{Ir}$ + G1 = I,66 Tab. III). Oligosaccharide waren darin nicht enthalten. (Abb. 8e). Das Zuckerbild der von nir untersuchten Honigproben blieb. in Rahmen der Kleehonige. Bei den Hornkleehonigen zeigen die beiden. nach dem prozentualen Anteil Lotus-Pollen unterteilten Gruppen gewisse Unterschiede in Zuckerspektrum. Die Proben mit einem Lotus-Leitpollen besitzen einen ziemlich hohen Iruktose-tund Saccharosegehalt ( $\mathrm{Fr} / \mathrm{Gl}=\mathrm{I}, 23 ; \mathrm{S} / \mathrm{I} \mathrm{ir}+\mathrm{G} 1=0,05)$, in den Proben mit geringerem LotusAnteil ist das Verhälnis zwischen Glukose und liruktose ausgeglichen $(\mathrm{Fr} / \mathrm{G} 1=\mathrm{I}, 04)$ und der Saccharosegehalt niedrig. Der einzige untersuchte. italienische Sullahonig zeigte ähnliche Zuckerverhältnisse (Tab. III).

Melilotus-Nektar enthält nach Furgala und Mitarbeitern etwas mehr Glukose als Fruktose and verhältnismässig wenig Saccharose (Tab. III). Das Zuckerbild von Melilotus-Honigen ist, nach Austin demjenigen der übrigen Kleehonige ähnlich. Is zeigt ein ausgeglichenes Iiruktose' (xlukoseverhältnis und einen geringen saccharosegehalt (Tab. III).

\section{Lahiaten.}

Hinseitige Labiaten-Honige sind in Mittel-und Nordeuropa selten, trotzdem viele Arten dieser Familie zu den ansgiebigsten Nektarspendern gehören. Häufiger werden Labiaten-Sortenhonige in Siud und Siudosteuropa und an der pazifischen Kïste Nordamerikas geerntet, wo Rosmarinus

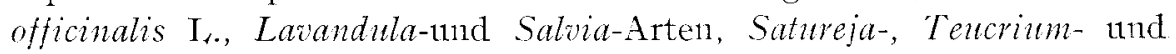
Thymus-Arten, sowie Stachys annums I.., als Wild-und Kulturpflanzen, oder Unkränter weite Verbreitung haben. Mikroskopisch können nach der Pollengestaltung mehrere Labiaten-Typen unterschieden werden : die 
L (Laminm)-Form (Lamium, Stachys, Teucrinm usw.), die Al (Majorana)Form (Majorana, Mentha, Monarda, Satureja, Thymus, Lavandula, Origanum, Dragocephahum usw.), und die s (Salita)-Torm (Saliia, Rosmarimus, s. Zander I935, I937, I94I).

Iie papierchronnatographische Verarbeitung des Nektars von I abiaten

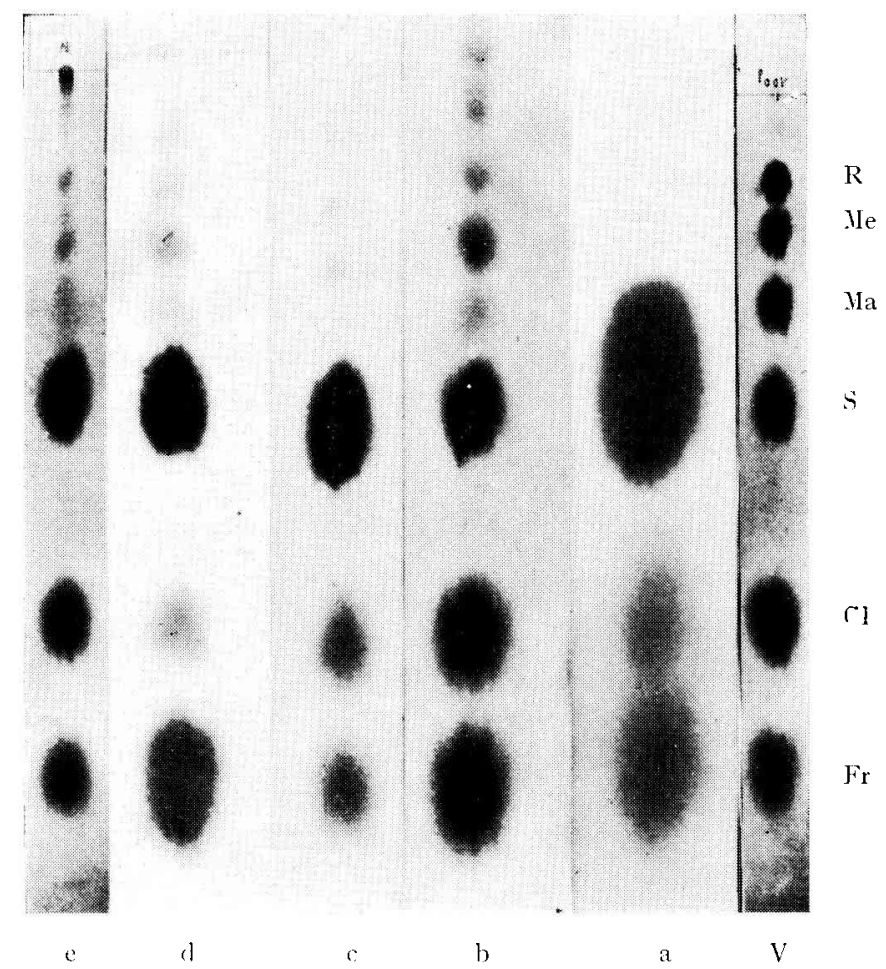

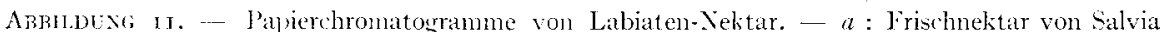
pratensis. - b : Nelitar von Salvia prat. nath 5 -monatiger Jagerung bei $+t^{\circ} \mathrm{C}$ - $-c$ : Nektar von

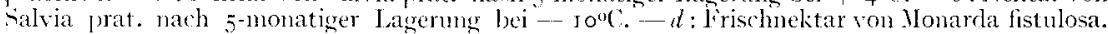
- : lirischncktar von Lavandula. $-V$ : Vergleichsaucter.

Fic. 11.-. - Chromatogrammes de nectar de Labies. - - $a$ : Nectar frais de Saloia pratensis. - $b$ : Nectar le Salvia pratensis apres 5 mois de conservation a $+{ }^{\circ} \mathrm{C}-6$ : Vectar de Saloia pratensis après 5 mois de ronservation à - $10^{\circ} \mathrm{C} .-d$ : Nestar frais de Monarda fislulosa. - e : Nectar frais de Larandula. $-V$ : Sucres témoins.

ergab recht einheitliche Resultate. Danach besitzt frisch aus der Blïte entnommener Nektar von Salvia-Arten, Monarda fistulosa $\mathrm{I}_{1}$. und Lavandula sp. einen hohen Saccharosegehalt $(\mathrm{S} / \mathrm{Tr}+\mathrm{G} 1=\mathrm{I}, \mathrm{I} 2-3,27)$, nehr Firuktose als Glukose ( $\mathrm{Fr} / \mathrm{Gl}=\mathrm{I}, 42-28,78$ ) und in der Regel mehrere Oligosaccharidflecke (Tab. IV, Abb. I $a, d, e$ ). Der Saccharoseabbau und die Bildung von Oligosacchariden lässt sich besonders schön am gelagerten Nektar von Salvia pratensis verfolgen (Abb. II $a-c$ ). In frischen Zustand enthält dieser Nektar nur drei Zuckerarten; bei 


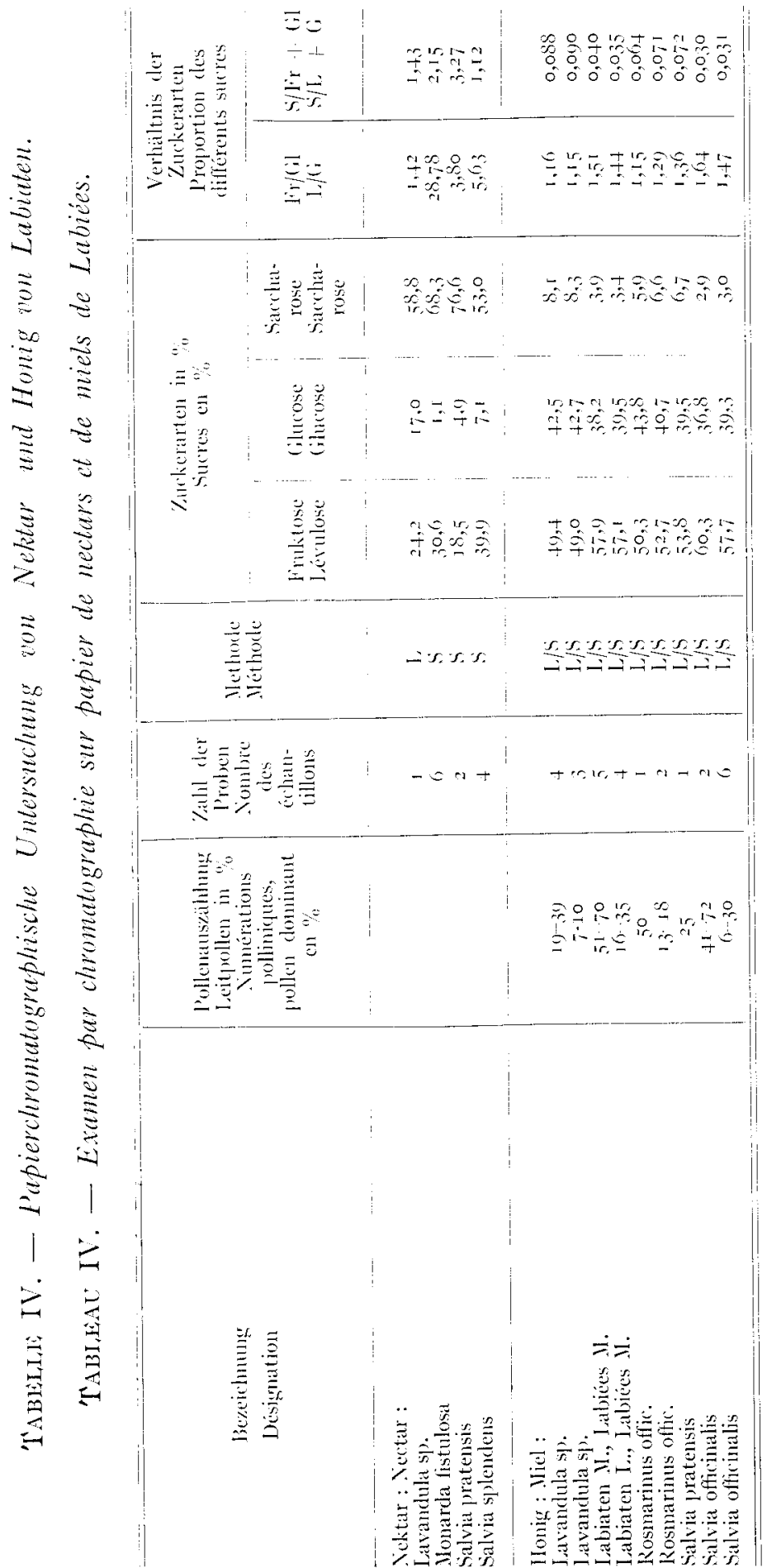


Lagerung in der Temperatur von $-4^{\circ} \mathrm{C}$ ist die Hydrolyse schon nach 6 Wochen in rollem (iange, in Chromatogramn erscheinen neben den drei Hauptzuckern, ein Maltose-und mindestens + Oligosaccharidflecke. Nach drei, fünf und newn Monaten ist der Saccharose-Abban noch nicht abgeschlossen, der Saccharosefleck wird nach und nach schwïcher, dic Oligosaccharidkette unfasst 6-7 Zuckerflecke, unter welchen ein auf der Höhe der Melezitose lokalisierter besonders stark hervortritt. In dem bei - Io ${ }^{\circ}$ gelagerten Nektar beginnt die Hydrolye später, so dass erst nach 5 und 9 Monaten in den Chromatogrammen einzelne schwache Oligosaccharidflecke zu finden sind.

Z11 ähnlichen Ergebnissen kam II ikes (1052, 1953) bei der Lntersuchung des Nektars ron \& I abiaten-Arten darunter Lacandula Spica, Mentha viridis, Thymus algaris und Pycnanthemum pilosum. Bei letzterem fand sich, ähnlich wie in meinen Untersuchungen an .Monarda fistulosa, in Nektar 15-23 mal mehr Iiruktose als Cilukose. I ler Nektar von Labiaten scheint demnach eine sehr stark wirkende Invertase zu enthalten, welche einc 'Transglukosidierung der saccharose, unter Bildung zahlreicher Oligosaccharicle und Anreicherung von liruktose herbeifuhrt.

Soweit sich aus dem ron mir untersuchten Material schliessen lässt. besitzen Iabiaten-Sortenhonige ein charakteristisches Zuckerspektrun. In allgeneinen zeigen diese Honige einen beträchtlichen saccharosegehalt, der in Rosmarin-, Iavendel-tnd Salbeihonigen (Saliapratensis) besonders hohe Werte erreicht ( $S$ Iir $+(i 1=0,06-0,09$, 'Iab. IV, Abb. r2 $a-c)$. Ausserdem erscheinen in clen Chromatogrammen von IabiatenHonigen in der Regel mehr oder weniger deutliche Flecke auf der Höhe der Maltose (Abb. I2 a, b). I)er liruktose-( iehalt ist in Salbei-nud I, abiaten M-Honigen höher als der Chlukosegehalt (I'r/Gl :=- I,4-I,6, 'Tab. IV) : Rosmarin-nnd Iavendelhonige enthalten annähernd gleiche Mengen der beiden Hexosen (II ( II =- I, I, - I,29), Tab. IV). Fin Teberwiegen der liruktose stellen White und Mahe in zwei kalifornischen von salbei und Thymian stammenden Honigen fest ( $\operatorname{Fr}(\mathrm{rl}=\mathrm{I}, \mathrm{f}$ and $\mathrm{I}, 7$ ). In allen Chromatogrammen von I abiatenhonigen ersclien eine Reihe von Oligosacchariden (Abb). I2 $a-c)$.

Bei Betrachtung der in l'abelle IV zusammengestellten Werte fällt auf, dass bei den untersuchten I abiaten-Honigen keinerlei Zusammenhänge zwischen den Zuckerbild und den P'ollenanteil der I,eitpflanze zu finden sind. Besonders dentlich ist dies bei den jugoslawischen Salbeiund densïdfranzösischen 'Thymian1-, sariette-1nnd I arandi nhonigen. Offenbar wirl bei den labiatenhonigen das Zuckerspektrum so stark rom Rohstoff beeinflusst, dass schon cin geringer Nektaranteil für die Cestaltung des endgïltigen Zuckerbildes des Honigs entscheidend ist.

Die Befunde der papierchromatographischen Entersuchung decken. sich mit den Firgebnissen der quantitativen Pollenanalyse, wonach Salbei- 


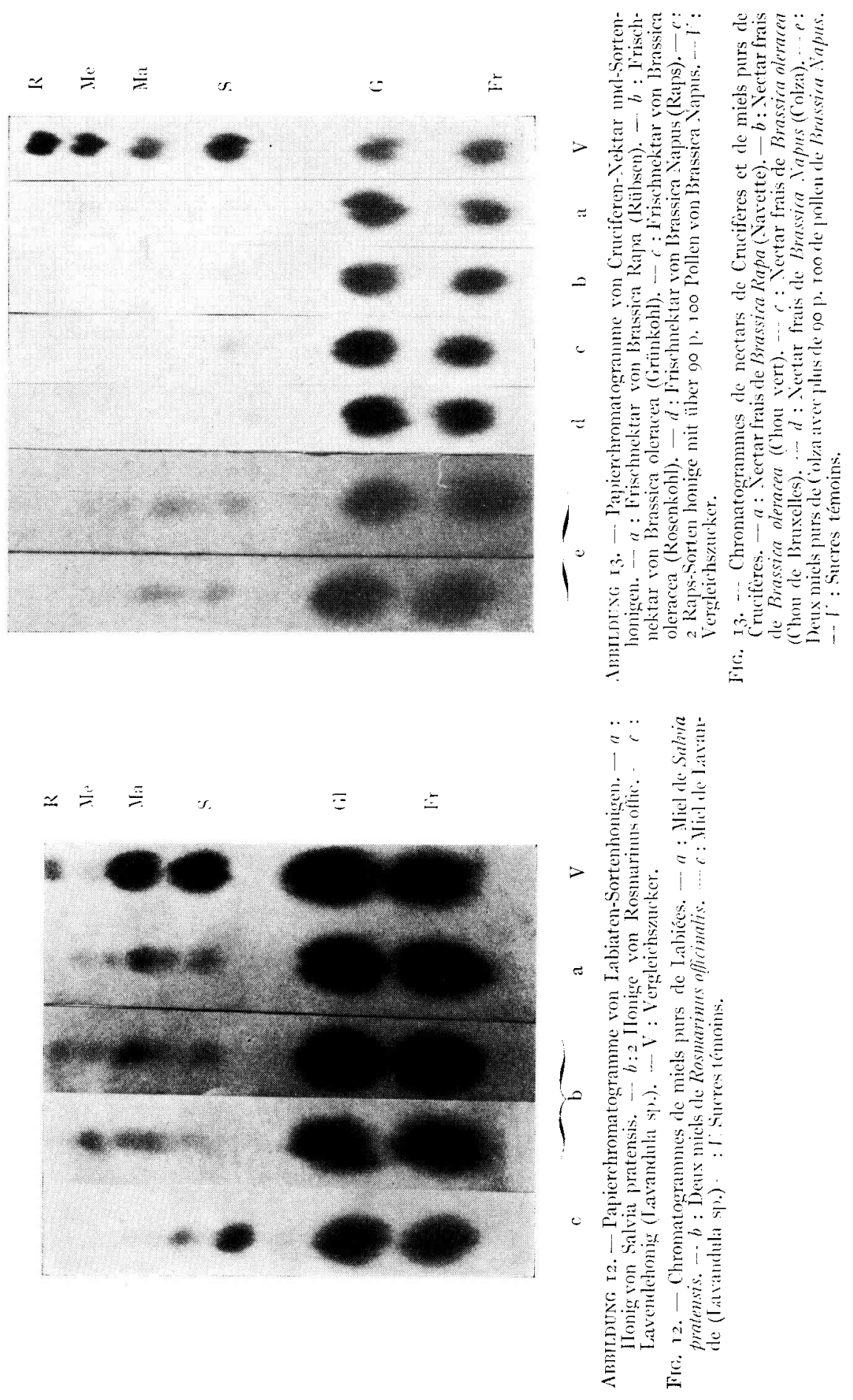


und I avendel-Honige zu den pollenarmen Honigsorten gelören, so dass schon ein geringer Anteil Saliza-oder Larandula-Pollen auf einseitige 'Tracht von diesen Pflanzen hinweisen (Manrizio I958). Is ist möglich, dass bei einzelnen diescr verhälnnismässig seltenen und auf gewisse begenden des Mittelmeerraumes beschränkten Honigtypen das Papierchromatogramm zur Lnterstuitzung and Bestätigung des mikroskopischen Befundes herangezogen werden kann. IIt Frfolg könnte dies z. B. zur Identifiziernung von I avendinhonigen geschehen, welche nach der Pollenauszälnhng als Nischhonige mit einem Anteil ron 7-Io 1). Ioo Lacandula-l'ollen angesprochen werden sollten, nach dem chromatographischen Befund aber rölig den Iavandin-Sortenhonigen (mit 30-40 p. roo Larandula-I'ollen) entsprechen.

I) a das ron mir verarbeitete Material ziemlich beschränkt ist, wäre es lohnend die papierchromatographische Lntersuchung auf ein umfassenderes Material von salbei-und Rosmarinhonigen auszudehnen, um festzustellen ob bei ersteren die aus l'ab. IV ersichtlichen Interschiede zwischen verschiedenen Salia-Arten gesichert sind, und ob letztere stets einen so hohen saccharosegehalt besitzen. Interessant wäre es auch Honige ans dinseitiger Tracht von I abiaten des I -Typus (z. B. Teucriumund Stachys-Arten) in die Untersuchung einzubeziehen.

\section{Cirucileren.}

Inter den Kreuzbliitlern ist Raps (Brassica Napus I.) eine der wichtigsten Bienentrachtplanzen in Mittel-und Nordenropa; seltener werden Sortenhonige von Hederich (Raphanus Raphanistrum I.), Senf (Simapis arensis I..) und Kohlarten (Brassica oleracea I..) von den Bienen eingetragen. Meine Untersuchungen beschränken sich auf RapsNektar and -Honig.

Soweit papierchromatographische Lntersuchungen vorliegen enthält der Nektar von Cruciferen zur Hauptsache liruktose und cilukose ('Tab. V Abb. I3, s. auch Wykes 1952, I953). Nach meinen Beobachtungen herrscht in Rapsnektar Glukose mengenmässig ror $(\mathrm{Fr}(\dot{\mathrm{l}}=0,79)$; Saccharose ist in knap1 messbaren. Mengen vorhanden; ausserdem zeigen die Chromatogramme oft einen sehr schwachen Zuckerfleck auf der Höhe der Maltose (Abb. I3 $d$ ). Aehnlich ist auch das chromatographische Bild des Nektars von Rübsen-und Kohlarten (Abb. I3 $a-c$ ). Höhermolekulare Zuckerarten wurden bisher in Cruciferen-Nektar nicht gefunden. Das mengenmässige Leberwiegen von Glukose gegenüber liruktose scheint fiir Cruciferen-Nektar charakteristisch zu sein, denn es wurde von Wykes (r953) auch für Nektar von Sinapisalba festgestellt (Irr (il $=0,87$ i. M.).

I)as Zuckerbild von Raps-Sortenhonigen wird offenbar von den im Nektar herrschendlen Verhältnissen stark beeinflusst. Der Saccharose- 
gehalt ist sehr niedrig ( $\$$ Iir $+(i 1=0$,OIO-O,OIs, i. MI. o,oIt), das Verhältnis zwischen linktose und Glukose ausgeglichen (Iir (i1 $=0,97^{-}$ I,O4, i. M. I,O0, Tab. V). I )ie quantitative Bestimnung aller Zuckerarten in vier Rapshonigen zeigte, dass (ler Gehalt an Maltose und ()ligosacchariden höher ist als der saccharosegehalt ('T'ab. VIII). I)iese Zuckerarten müs sen während des Reifungsprozesses synthetisiert werlen, da Rapsnektar nur ganz geringe Mengen saccharose, knapp angedentete Maltoseflecke und keine Oligosaccharide besitzt (Abb. I3 $a, e)$.

Werden die 30 untersuchten Rapshonige nach dem prozentualen Anteil von Rapspollen unterteilt, so sind keine Lnterschiede des Zuckerbildes zwischen den (iruppen zu bemerken ('lab. V). I)as Verhältnis zwischen (ilukose und liruktose beträgt sowohl bei blïtenreinen Rapshonigen (mit mehr als go p. Ioo Brassica-Pollen), wie bei den ehor als RapsMischhonige anzusprechenden Proben (mit to-bo p. Ioo Brassica-Pollen) nahezu I,o. Aehnlich liegen die Verhältnisse bei einen von dustin untersuchten Senfhonig (Ir/G1 $=0,98)$. Auch in saccharosegelalt sind zwischen den Honigen der einzelnen (iruplen keine Enterschiede vorhanden. $\left(\$ / \mathrm{Ir}+\mathrm{G} 1=0,010\right.$ und $0,0 \mathrm{I}_{3}$ bei einseitigen Rapshonigen ; o,oIs bei Rapsnischhonigen; 0,0I3 bei senthonig nach Austin).

Fis kan1n daraus der sichluss gezogen werden, dass der Nektar von Brassica Vapus I., und rielleicht auch ron andern Cruciferen eine sehr aktive Saccharase enthält, die nicht nur eine schnelle ipaltung der Saccharose bewirkt, sondern auch das 7uckerbild des Honigs entscheidend beeinflusst. I,eider ist, meines Missens, über die Zusammensetzung der Zuckerarten in Phloemsaft der Cruciferen nichts bekannt. Is besteht die Möglichkeit, dass die Aufspaltung der saccharose schon in der Pflanze beginnt.

In der pollenanalytischen I, iteratur ist die I'rage anfgeworfen worden, ob Rapshonige zu den pollenreichen Honigsorten gehören und demnach erst dann als bluitenrein zu betrachten sind, wenn sie einen sehr hohen prozentualen Anteil von Brassica-Pollen enthalten (I'ritsch I957). d)iese Annahne wurde durch die (quantitative I'ollenanalyse nicht sicher bestätigt, da nur ein Teil der untersuchten Rapshonige einen etwas erhöhten absoluten Pollengehalt aufwies (.Manrizio I958). Die Eirgebnisse der papierchromatographischen Lntersuchung sprechen eher gegen eine Sonderstellung des Rapshonigs, weil offenbar schon Honige mit einen Anteil von to p. roo Brassica-Pollen in chemischer Hinsicht alle charakteristischen Merknule von "Rapshonig " besitzen.

\section{Ericoaceon.}

Mehrere Arten aus der l'amilie der Ericaceen gehören zu den europäischen Haupttrachtpflanzen. In Nord-und Nordwesteuropa sind es Calluna inlgaris (L.) Hull, Erica cinerea I,. und Erica Tetralix I., in 


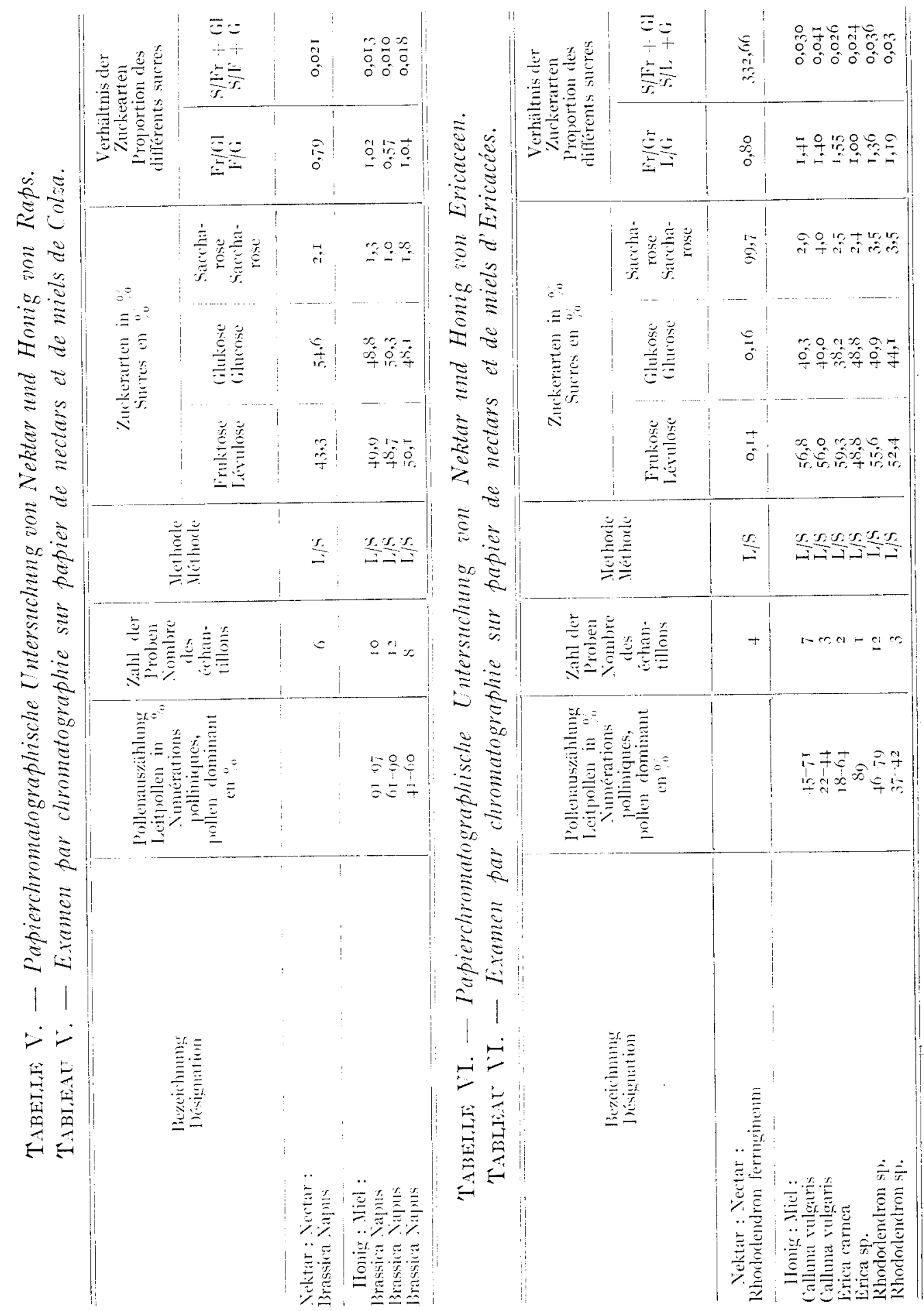


Süd-und Südwesteuropa Erica arborea und Erica vagans ; in Alpengebiet Erica carnea I., Rhododendron ferrugineum und Rhododendron hirsutum. Alle Ericaceen sind ausgiebige Nektarspender und führen, da sie meist in grossen, geschlossenen Beständen wachsen zur Einte charakteristischer Sortenhonige. Meine papierchromatographischen Lntersuchungen umfassten bisher zur Hauptsache Alpenrosen-und Heidehonige.

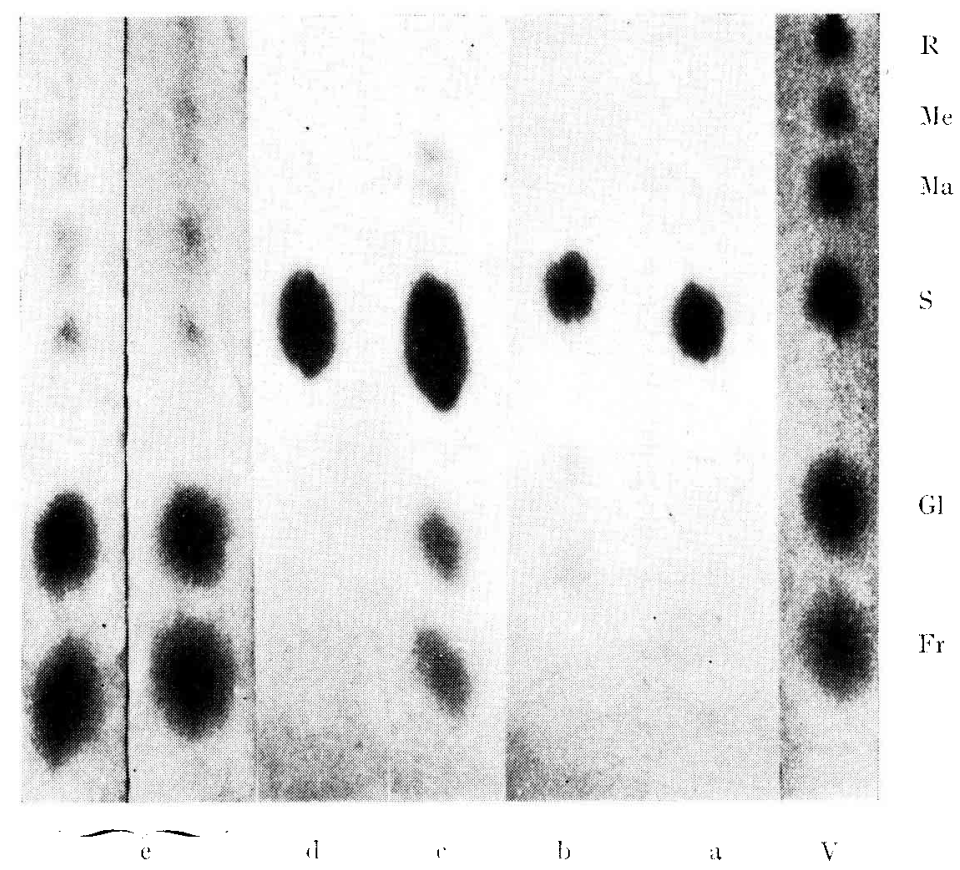

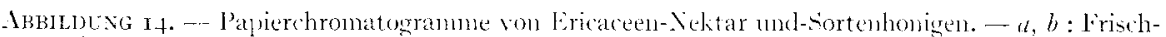
nektar von Rhododendron ferruginem verschiedener l'rovenienz. -- i: Veliar von Rhododen-

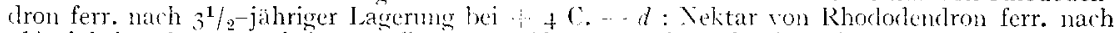

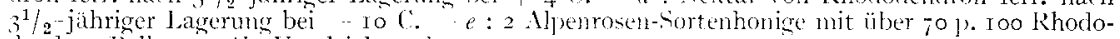
dendron-Pollen. - 1 : Vergleichszucker.

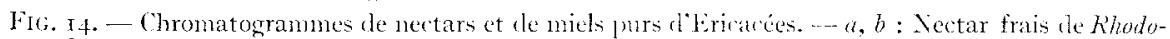

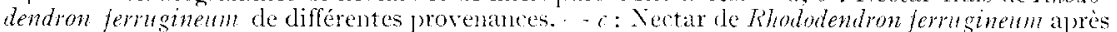

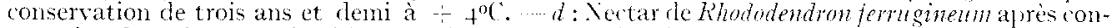

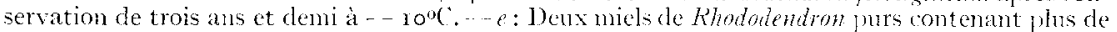
zo p. roo de pollen de Rhododendron.... V : Sures témoins.

Der Nektar von Rhododendron fermginem enthält in frischen Zustand praktisch nur einen Zucker, Saccharose. Von den vier von mir untersuchten Nektarproben bildeten drei im Chromatogramm ausschliesslich Saccharoseflecke, in dritten fanden sich ausserdem sehr schwache, knapp messbare Flecke von I'ruktose und Gukose ('l'ab. VI, Abb. I4 $a, b$ ). Der im Kühlschrank gelagerte Nektar zeigte während der ersten I2 Monate keine sichtbaren Veränderungen des Zuckerbildes. Fist nach I I $/ 2$ und $3 \times / 2$ Jahren trat bei $+4^{\circ} \mathrm{C}$ eine Aufspaltung der Saccharose, unter Bildung von Fruktose, Glukose und 2 Oligosacchariden ein, während 
bei - Io' ${ }^{\circ}$ anch zu diesem Zeitpun1kt ausschliesslich Saccharose im Chromatogramm erschien $(A b)$. I $c, d)$. I)ieses Verhalten lässt vermuten, dass Rhododendron-Nektar praktisch keine Invertasen enthält, so dass in Alpenrosenhonig fast ansschliesslich die Bieneninrertasen wirksam sein diirften.

Die papierchromatische Enterstuchung ron Alpenrosenhonigen bestätigt diese Annahme. Die I2 geprïften Alpenrosen-sortenhonige haben einen mittleren succharosegehalt (i. M. S $\$$ / ir $+(.1=-0,036)$ und einen etwas höheren Iiruktose-als chlukosegehalt (i. M. $\operatorname{lir} / \mathrm{rl}=\mathrm{I}, 36$, 'Tab. VI). In den drei $A l_{1}$ enrosen-Mischhonigen ist clas Fruktose ClukoseVerhältnis, bei gleichem saccharosegehalt, stärker ausgeglichen. In allen Chromatogrammen ron Alpenrosenhonigen erschienen neben den drei Hauptzuckern schwache Maltoseflecke und cine ganze Reihe von Oligosaccharidfecken (Abb. It e). Tas Zuckerbild der Alpenrosenhonige ist demmach, abgesehen von einem leicht erhöhten I'ruktosegelalt wenig charakteristisch und erinnert stark an Blïten-Mischhonigu.

I)as verarbeitete Material von Erica-Honigen beschränkt sich auf zwei schweizerische I'roben von Erica carnea und einen griechischen Honig mit Erica-I, eitpollen, dessen botanische Zugehörigkeit nicht sicher bestimmit worden konnte. I)er saccharosegehalt ist in allen clrei Proben zienlich niedrig, Conterschicde sind dagegen in Bezug aul das liruktose. Crlukose-Verhältnis fustzustellen. Wahrend in griechischen Honig dit beiden Zuckerarten gleich stark vertreten sind, herrscht iil den sichneeheide-Honigen linnktose deutlich ror ('Tab. VI). In beiden Honigsorten

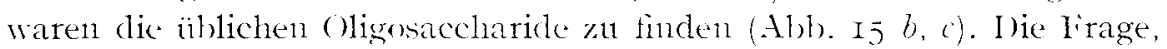
ob die Lnterschiede des Zucketbildes für die cinzelnen Erica-Arten charakteristicll sind, nntss an einen nunfangreicheren Honignaterial,

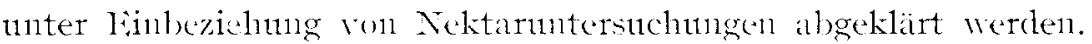

J)ie grosiste praktische Bedentung nuter den Fricaceen-Honigen komment dem Heidehonig zu. Teber das Zuckerhild des Calluna-Nektars ist leiker bisher nichts bekannt geworden, dis Zuckerspektrum des Honigs ist durch dentliche saccharoste-und Maltoseflecke und eine, oft bis zum startpunkt reichende Kette ron oligosaccharidflecken geken11zeichnet (Ab). I5 $a$ ). I her saccharosegelialt beträgt im Mittel 2,9 p. Ioo $(S /$ Ir $+(\vdots 1 \quad 0,03)$; der linktoscogehalt ist höher als der cilukosegehalt (Iir) (rl - I, , Tab. VI).

Zwischen Honigen mit einem (alluna-Ieityollen (4i-7 I p. IOO) und solchen, die (alluna als Begleitpollen enthalten, sind keine fassbaren Enterschiede des Zuckerbildes vorhanden. Iis scheint vielnehr, dass auch Honige mit einem nuter 45 p) roo liegenden Anteil Calluna-Pollen sich in chenischer Hinsicht wie Heick-Sortenhonige verhalten ('Tab. VI). Diese Beobachtung spricht für dic in rer I iteratur aufgestellte Vermutung. wonach der calluna-Anteil auf (irund der pollenanalytischen Auszählung 

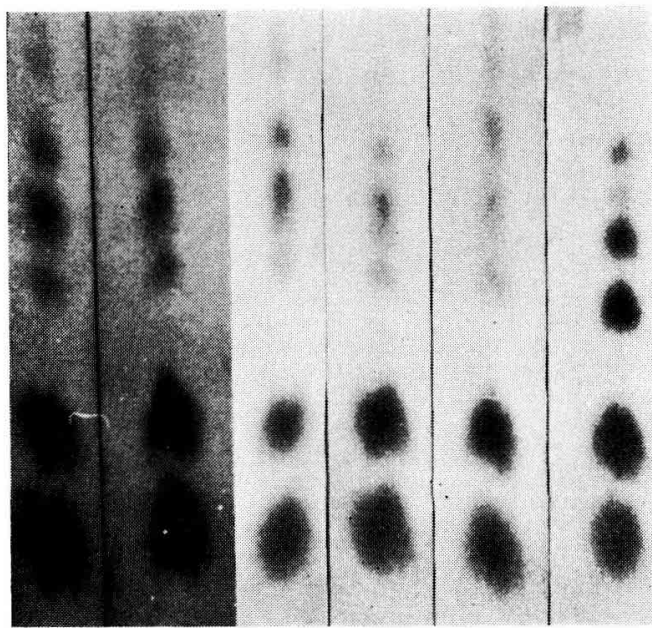

li

$M_{c}$

Ilat

$s$

(i)

Irr

c

b

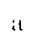

$r$

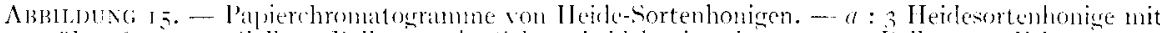

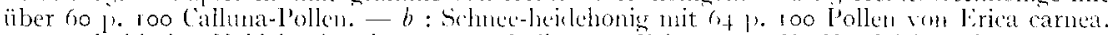

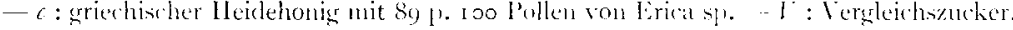

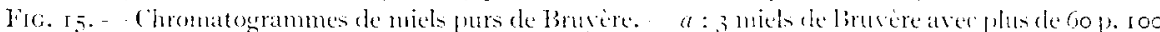

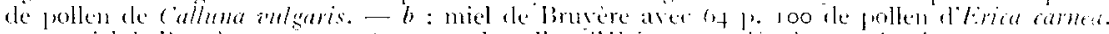

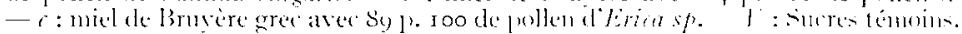

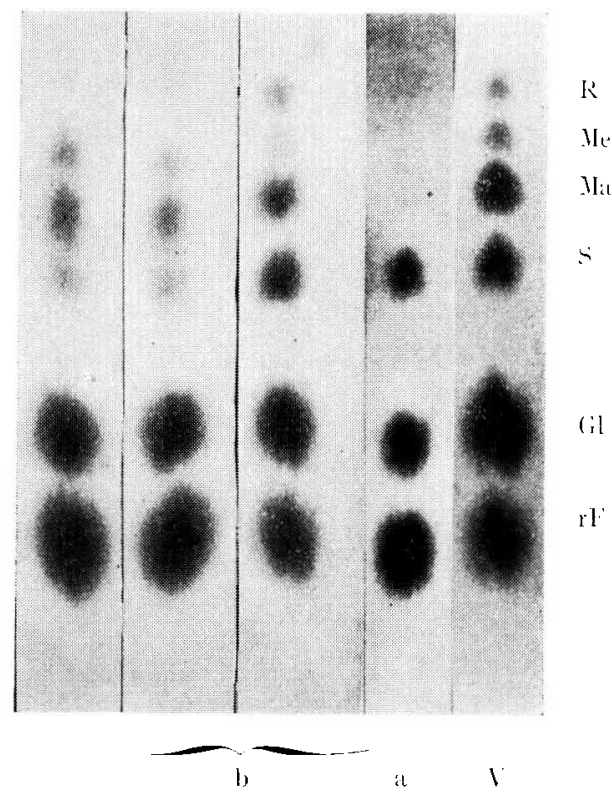

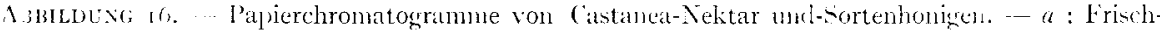

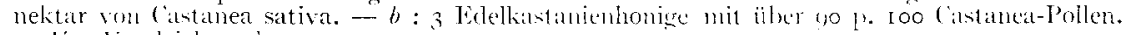
- 1: Vergleithsucker.

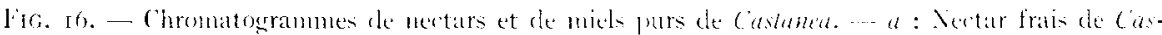

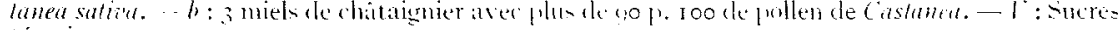
timoins 
zu niedrig eingeschätzt wird und deshalb einer Korrektur bedarf (Lunder). Die quantitative Pollenanalyse ergab allerdings keine Anhaltspunkte für eine solche Korrektur, vielnehr erwiesen sich Heide--ichlenderhonige als "nornual " im absoluten Pollengehalt. Is ist deshalb möglich, dass der Calluna-Anteil nach der prozentualen l'ollenanszählung richtig eingeschätzt wird, der Calluna-Nektar aber dine wirksame Tivertase enthält, die schon bei geringem Anteil das Zackerbild des Honigs beeinflusst.

\section{speziallarlıten.}

Enter der Bezeichnung "spezialtrachten "werden hier Honigsorten und ihre Rohstoffe zusammengefasst, die von besonders ergiebigen, in ihrer geographischen Verbreitung auf gewisse Gebiete beschränkten Trachtpflanzen stanmen. In der Regel sind die betreffenden crattungen mol Arten isolierte Vertreter cinzelner Pflanzenfamilien. Tazu gehören z. B. die Edclkastanie, I, indenarten, Buchweizen, Citrus-und EucalyptusArten.

\section{Edelkastanio (Castanea salioa Viller).}

bie Fidelkastanie ist die einzige insektenbliitige, nektarabsondernde Gattung der Fanilie der lagaceen. Zur Blütezeit werden die Edelkastanien stark ron Bienen und andern Insekten besucht und liefern, in fiegenden mit grösseren Beständen reiche Honigernten.

Iirisch aus Bliiten entnommener Castanea-Nektar fiilhrt, nach meinein Intersuchungen nur die drei Hauptzuckerarten, wobei melir als dic Halfte des (iesantzuckers aus liruktose besteht (Fi (i1 $=2,27$. Tab. VII, Abb. If $a$ ). Auch einseitige Kastanienhonige, mit einem über go p. roo betragenden (astanea-Pollenanteil, sind durch einen hohen liruktosegehalt charakterisiert ( $\mathrm{I}+\mathrm{T}(\mathrm{H})=\mathrm{I}, \mathrm{S} 7)$, während der saccharosegehalt in den üblichen (irenzen liegt (s Ir $+(\$ 1=0,029$, 'lab. VII). Neben den drei Hanptauckern enthalten Kastanienhonige stets weitere Zuckerarten, so z. B. dentliche Ialtose Isomaltose-I'lecke und häufig 3-6 Flecke höhermolekularer \%ucker, die bis zum startpunkt reichen (Abb. I6 b).

Wie ans 'Tabelle VII hervorgeht ist ein deutlicher Interschied in den Zuckerverhälnissen zwischen einseitigen Kastanienhonigen (über 9o p. IoO ('astanea-Pollen), and Honigen nit geringerem Kastanienanteil rorhanden. Während extren biutenreine Kastanienhonige fast doppelt so viel liruktose als Glukose enthalten, sinkt das IirGl-Verhältnis in

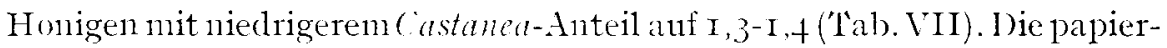
chromatographische Untersuchung bestatigt demnach die Beobachtungen der quantitativen I'ollenanalyse, wonach Edelkastanienhonig zu den extrem pollenteichen Honigsorten gehört, und erst bei einem sehr hohen castanea-Pollenanteil als blïtenrein betrachtet werden kann. 
(IV, I959) UNTERSTCHUNGEN AN HONIGEN UND NEKTAR

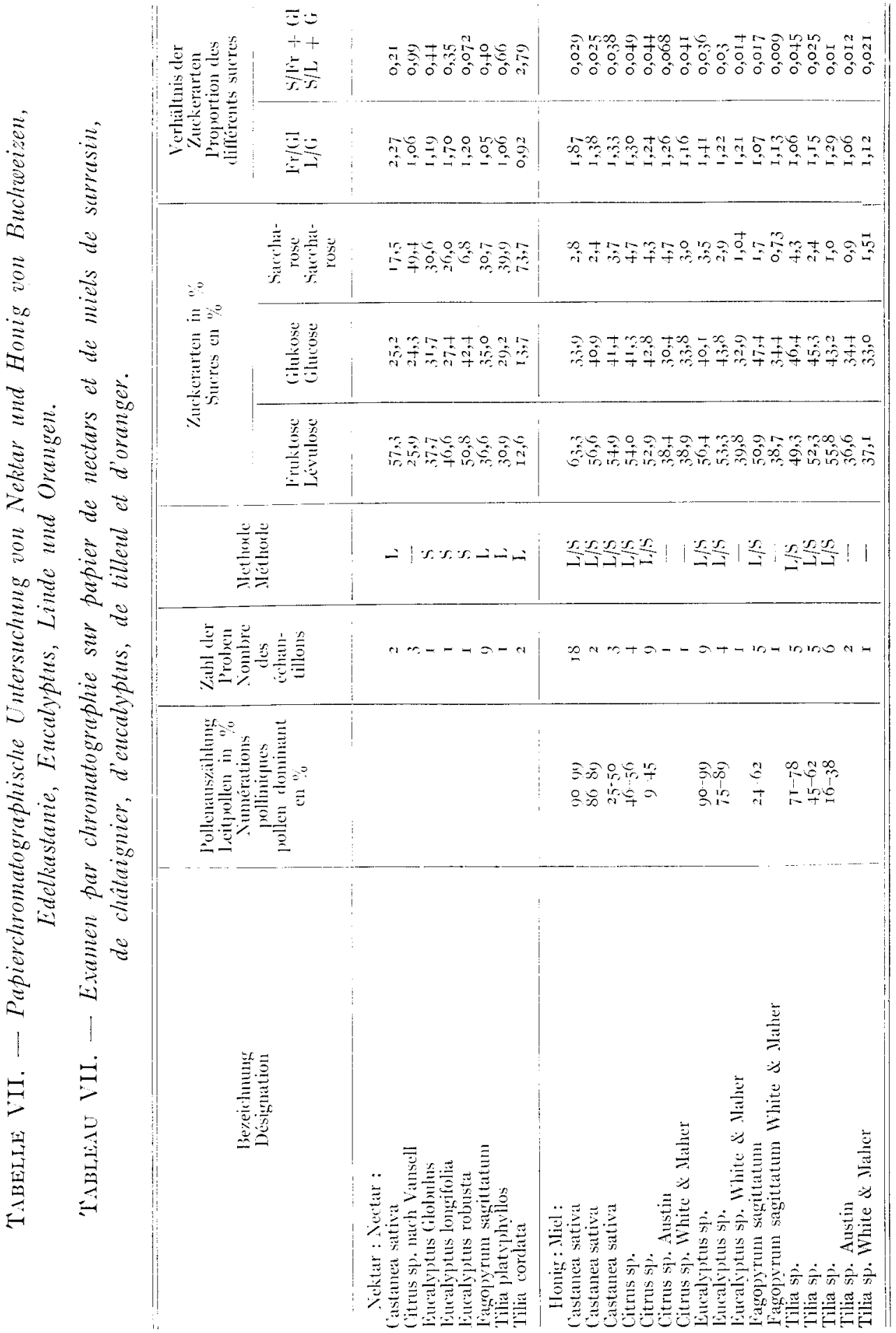

Annales des Abeilles. - 1959. 
Aus dem unterschiedlichen I'r/G1-Terhältnis erklärt_sich die Tatsache, dass extren einseitige Kastanienhonige längere Zeit hindurch flüssig bleiben, während Kastanien-Mischhonige nach einigen Monaten kristallisieren.

\section{Lindenarten (Tilia sp.).}

Die I, indenarten gehören mit einer Zuckerproduktion ron 7,2 $\mathrm{mg}$ je Bliite und 24 Stunden zu den ausgiebigsten Nektarspendern. Die Tatsache, dass I,indenhonig in Furopa verhältnismässig selten geerntet

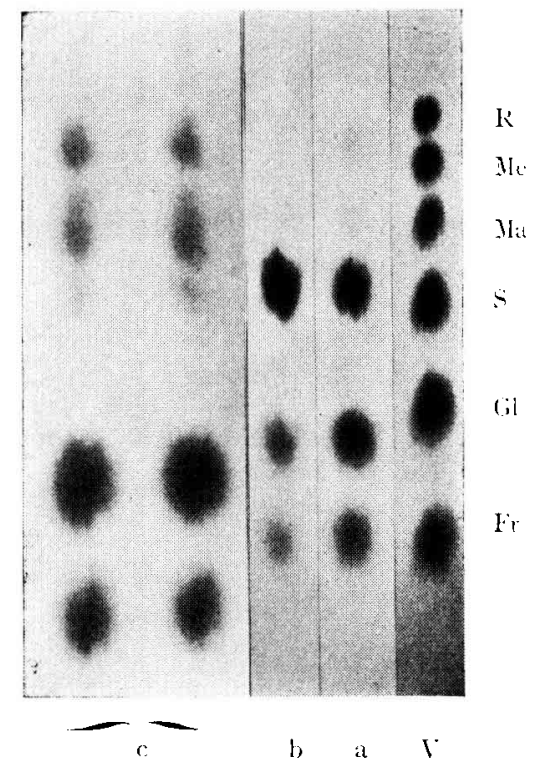

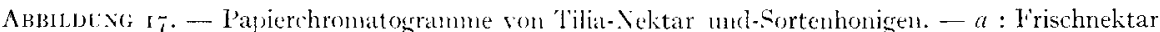
von Tilia platyphyllos. - $b$ : l'rischnektar von 'Tilia corclatit. $-i: 2$ Lindensortenhonige mit über 70 \%. 100 'Tiliapollen. --.- 1 " Vergleichszucker.

Fig. I7.-- (hromatogramme de nectars et de miels purs de Tilier. -- a : Nectartfrais de Tilia platy-

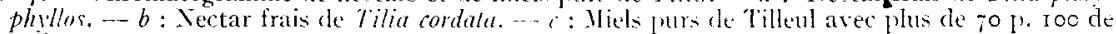
pollen de 'Tilleul. - l' : sures témoins.

wird, hängt weniger mit der Nektarabsonderung der Blïten, als mit der geringen Verbreitung der Linde als Waldbaum zusammen. In Gebieten mit ansgedehnten wildwachsenden oder kultivierten Lindenbeständen kommen öfters I indensorten-oder I,indenmischhonige zur Frnte, die ein ausgesprochenes I,indenaroma und einen : Minzen "-Geschmack besitzen.

Die bisherigen papierchromatographischen L'ntersuchungen von I,indennektar beziehen sich auf drei Arten, Tilia platyphyllos Scop., Tilia cordata Miller and Tilia íulgaris Hayne ('Tah. VII, Täufel and Reiss, Wykes 1953). Sie zeigten, dass frisch entnommener I, indennektar, neben den drei Hauptzuckern oft mehrere höhermolekulare Zuckerarten enthält $(A b b)$ I $7 a, b)$. Tas Terhältnis zwischen Iiruktose und Glukose ist 
bei allen drei Lindenarten mit i. M. I,OO (0,92-I,o6) völlig ausgeglichen. In Bezug auf den Saccharosegehalt sind dagegen zwischen den wntersuchten Tilia-Arten Unterschiede vorhanden. Während in Nektar ron Tilia platyphyllos die drei Hauptzuckerarten fast zu gleichen Teilen vertreten sind, enthält der Nektar von Tilia cordata, und nach Wyes auch derjenige von Tilia vulgaris, nehr als doppelt so viel saccharose als Hexosen ('Tab. VII).

I) as Zuckerbild der untersuchten I,indenhonige zeigt keine anffallenden Merkmale. Das Verhältnis zwischen Iiruktose und (ilukose betrug wie in Nektar beinahe $I, O O\left(I, O 6-I_{1}, 5\right)$, der saccharosegehalt blieb mit o,OI-0,045 in den üblichen Grenzen ('Tab. VII). In allen Chromatogranmen von I,indenhonigen erschienen mehrere, z. T. recht starke I'lecke höhermolekularer Zuckerarten, unter welchen vor allem der auf der Höhe der Maltose lokalisierte I)oppelfleck (Maltose Isomaltose), und ein auf der Höhe der Melezitose liegender Ileck (Gruppe der Kestose Frlose) hervortreten (Abb. I7 c). Nach der quantitativen Bestimmung aller Zuckerarten in zwei Jindenhonigen ist der ('rehalt an Maltose und Oligosacchariden wesentlich höher als der Saccharosegehalt (Tab. VIII).

Meine Befunde decken sich mit den Analyseresultaten von Austin und White und Maher (1954), die in 3 nordamerikanischen I,indenhonigen einen verhältnismässig niedrigen saccharosegehalt, neben zienlich hohen Anteilen von Maltose und Oligosacchariden fanclen.

Vin Vergleich zwischen den in l'abelle VII, nach dem prozentualen Anteil Tilia-Pollen unterteilten Honigen zeigt, dass zwischen Lindensorten-und Mischhonigen gewisse Unterschiede bestehen. Das Verhälnis zwischen liruktose und Glukose ist in der Gruppe mit Tilia-I,eitpollen mit im Mittel I, I g gut ausgeglichen, der Saccharosegehalt, mit in Mittel $\mathrm{S} / \mathrm{I}$ it $+\mathrm{C} 1=0,035 \mathrm{ziemlich}$ hoch ; die I inden-Mischhonige besitzen einen höheren firuktose-und einen niedrigeren saccharosegehalt. I)ie auf Grund der quantitativen Pollenanalyse aufgestellte Annahme, class I indenhonige zu den pollenarmen Honigsorten gehören und schon bei einem Tilia-Anteil von 30-40 p. Ioo als blïtenrein zu betrachten sind, findet demnach durch die papierchromatographische Untersuchung keine sichere Bestatigung.

\section{Euralyptus-Arten (Eucalyplus sp.).}

Alle Eucalyptus-Arten sind ausgezeichnete Nektarspender und tragen in Iändern mit grossen Beständen entscheidend zur Funtstehung der Honigernte bei. In Iinropa sind einseitige Iincalyptus-Honige selten (Ile de Hyère, französische Riviera, Griechenland), häufiger kommen sie in Nordafrika, Kleinasien und südamerika ror; in Australien bilden sie den häufigsten Honigtypus. 'Trotzdem Euculyptus - Arten zu den 


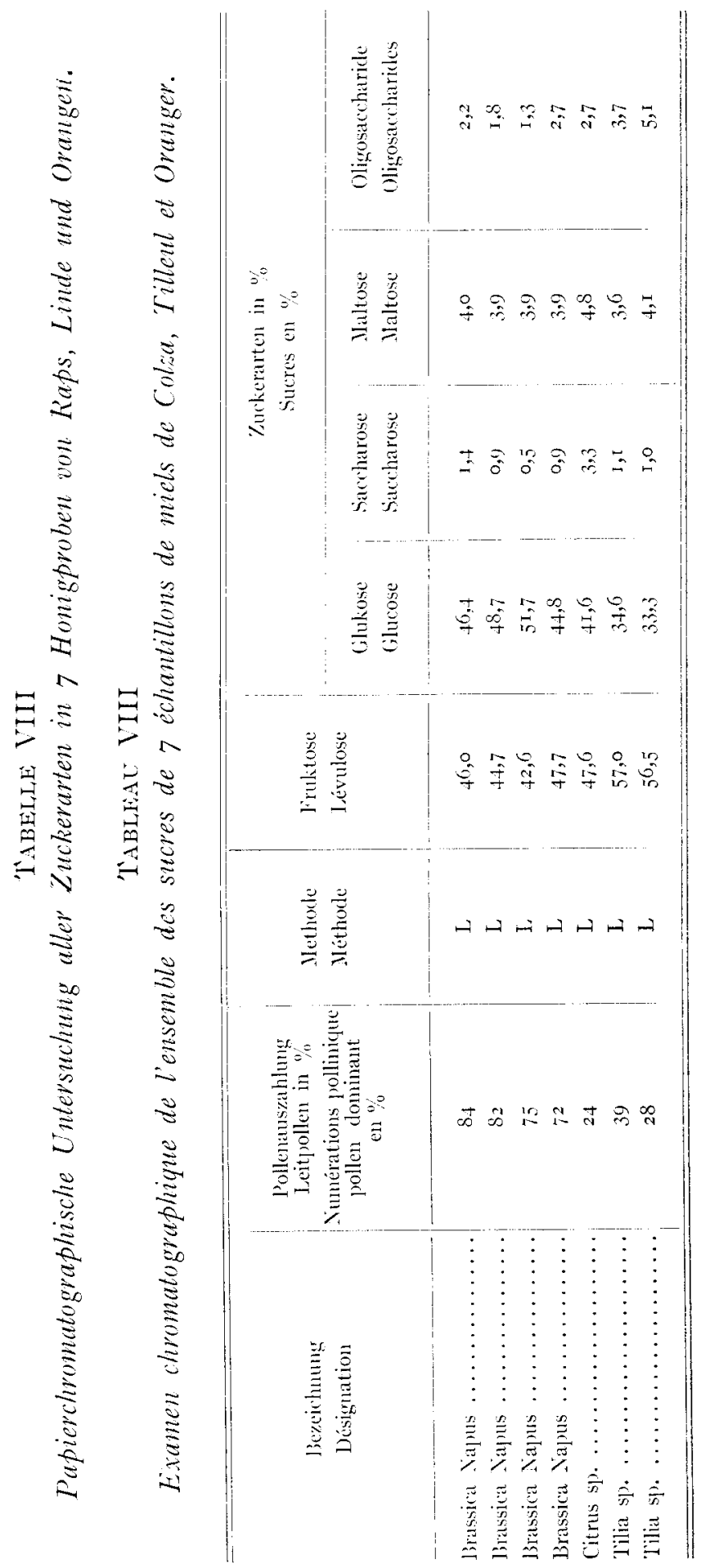


wichtigsten Honigspendern gehören, liegen bisher nur spärliche Untersuchungen über ihren Nektar vor.

Die von mir ausgeführten papierchromatographischen Untersuchung des Nektars von drei Eucalyptus-Arten (E. Globulus Lab., E. longifolia L. K. O., E. robusta Sm.) zeigten erhebliche Unterschie de des Zuckerbildes. Bei allen drei Arten enthält der Nektar mehr Iiruktose als (ilukose (bei E. longifolia Fr/G1 = I,70, 'Tab.VII). In Bezug auf dens'sceharosegehalt sind zwei 'Typen vorhanden. Dem ersten, mit annähernd gleichen Mengen der drei Hauptzucker gehören E. longifolia une E. Globulus an, dem

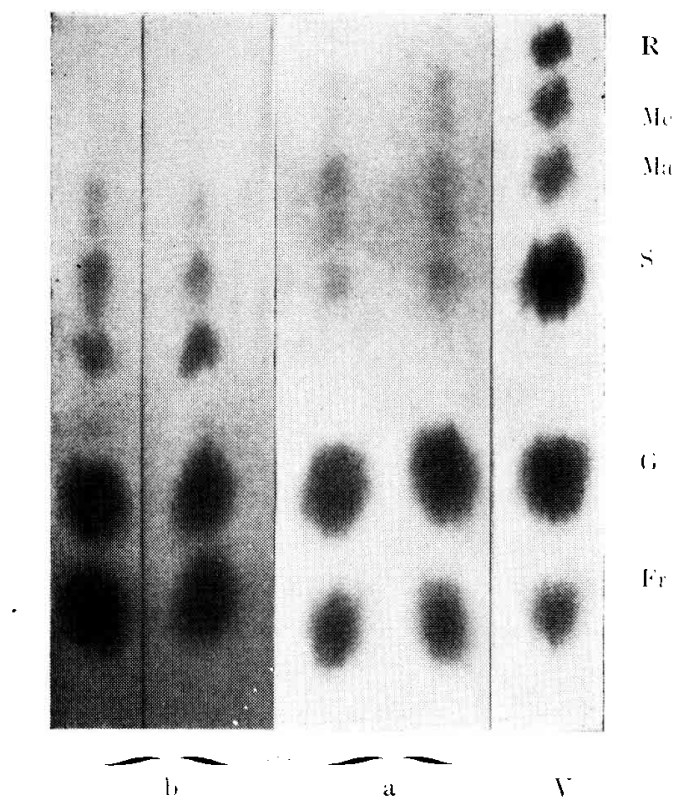

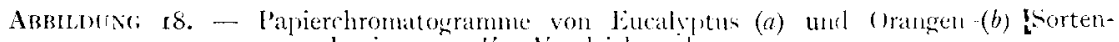
honigen. $-V:$ Veroleichsaliter.

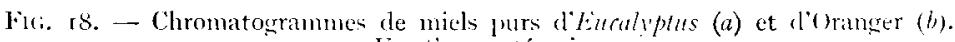
$V$ : Surres témoins.

zweiten, mit auffallend niedrigem Saccharosegehalt E. robusta ('Tab. VII). Keine der drei geprifften Nektarproben enthielt höhermolekulare Zuckerarten.

Die I3 in Tabelle VII angeführten, aus Sïdfrankreich, Nordafrika, Irak, Argentinien und Australien stammenden Eucalyptus-Honige hatten ein gut ausgeglichenes Zuckerspektrum. Alle Proben enthielten mehr Firuktose als Glukose (Ir/G1 i. M. = I,34, bei einzelnen Proben I,(1)I,9), schwache Saccharoseflecke (S/rir + (\$1 i. M. = 0,035), einen Ioppelfleck auf der Höhe der Maltose und 3-4 Oligosaccharidflecke (Abb. Is a). Der hohe Iruktosegehalt der Eucalyptus-Honige lässt vernuten, dass weitere Eucalyptus-Arten, ähnlich wie Enc.longifolia fruktose- 
reichen Nektar absondern. Iïr den linfluss fruktosereichen Nektars spricht auch die Tatsache, dass das Verhältnis Iiruktose (Xlukose bei den gextrem einseitigen Fucalyptushonigen (Eucalyptus-Anteil über 9o p. Ioo) höhere Werte aufweist, als bei den + Proben mit niedrigerem EucalyptusAnteil ('Tab. VII). I)iese Beobachtung bestätigt den mikroskopischen Befund, wonach Eucalyptus-Honige cher zu den pollenreichen Honigsorten zu rechnen sind, die erst bei einem sehr hohen Anteil von EucalyptusPollen als blütenrein betrachtet werden können.

\section{(Citrus-Arien (Citus -p.).}

In den Hauptanbangebieten der Citrus-lirïchte in Kalifornien, Florida und den I,ändern des Mittelmeerraunes werden alljährlich helle, feinaromatische Honige geerntet, an deren lintstehung verschiedene Citrus-Arten beteiligt sind (Citrus durantium L., C. medica ssp. limonum Risso Hook., ( . nobilis Lonr., (. decumana Thell. usw). Nach V'ansell (I94t $a, b$,) und Vansell und Watkins besteht die Hälfte des Gesantzuckers im Orangennektar aus Saccharose, während Iruktose und Giukose annähernd zu gleichen 'leilen vertreten sind ('Iab. VII, Jir/Gil = I, o6, S/I ir $+(11=0,99)$.

I) zwölf von mir untersuchten als (itrus-Honig bezeichneten Proben wurden nach dem prozentualen Gehalt an Citms-Pollen in zwei (iruppen eingeteilt ('Tab. VII). Zwischen den vier Proben mit (itrusJ,eitpollen und den newn Proben mit Citrus-Regleitpollen sind keine auffallenden Lnterschiede des Zuckerspektrums festzustellen. sie besitzen alle einen etwas höheren Iiruktose-als Glukose-Gehalt und verhältnismässig hohe Werte des Saccharosengehaltes (i. M. $\operatorname{Ir} / \mathbf{G}=\mathbf{I}, 26$; $\therefore \mathrm{I} \cdot \mathrm{r}+\mathrm{G} 1=0,047 \mathrm{Abb}$. I 8 b). Wie Honigprobe, in welcher sämtliche Zuckerarten bestimmt wurden, wies ziemlich hohe Werte des Maltoseund Oligosaccharidgehaltes auf. Aehnliche Werte geben fustin und White und Maher (I954) für zwei weitere Orangenhonige an.

Nach der quantitativen Pollenanalyse ist ein Teil der Orangenhonige relativ pollenarm, so dass schon ein Anteil von weniger als $45 \mathrm{p}$. Ioo Citrus-Pollen einseitige 'Tracht von Orangenblïten vermuten lässt. Die geringen Unterschiede zwischen Honigen nit verschiedenen hohem Anteil an Citrus-Pollen scheinen diese Annahme zu bestätigen. Fs wäre erwïnscht, wenn weitere mikroskopische und papierchromatographische Jntersuchungen einseitiger Orangenhonigen ausgeführt wïrden.

\section{Burdweizen (Fayopyrum sayiltatum Gilib).}

Buchweizen spielt vor allem in den Jändern Osteuropas eine wichtige Rolle als Honigtrachtpflanze. Seltener sind Buchweizenhonige in Nord-, Vest-und Mitteleuropa und in Nordamerika. 
Im Nektar rom Fagopym sagittatum sind die drei Hauptzucker ungefähr in gleichen Mengen enthalten; das Verhältnis zwischen den

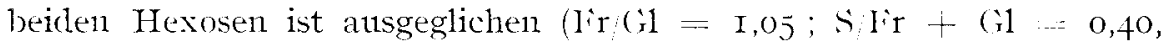
Tab. VII). Höhemolekulare Zuckerarten erscheinen in den Chromatogrammen nur andeutungsweise. Nach den bisherigen Untersuchungen ist das Zuckerbild ron Buchweizenhonigen wenig charakteristisch. I)as Verhältnis zwischen Glukose und Iiruktose ist nuit i. M. I,o7 gut ausgeglichen, der siaccharosegehalt verhältnismässig niedrig (i. M. 0,0I7, 'Tab. VII). Alle Chromatogramme von l3uchweizenhonigen wiesen einen schwachen Ioppelfeck bei Maltose Isomaltose anf, sowie einen z. 'T. deutlichen Oligosaccharidfleck auf der Höhe der Melezitose. Wieweit das Zuckerbild mit den pollenanalytischen Befunden (prozentualer Anteil ron Fagopym-Pollen) übereinstimnt, lässt sich anhand des spärlichen Iaterials nicht beurteilen.

\section{DISKUSSION DER ERGEBNISSE UND ZUSAMMENFASSUNG FRAGESTELLUNG UND METHODIK}

In der vorliegenden Arbeit werden vor allen folgende liragen untersucht :

a) lassen sich anhand papierchromatographischer Untersuchungen Zusammenhänge zwischen den Zuckerspektrum des Nektars verschiedener Pflanzenarten und der daraus entstehenden Honige nachweisen?

b) liefert die papierchromatographische Intersuchung der Zuckerarten im Honig Anhaltspunkte zur Beurteilung seiner botanischen Herkunft und kann diese Methode zur Unterstuitzung der pollenanalytischen Befunde herangezogen werden?

Vorausgesetzt wurde, dass der finfluss der Rohstoffe sich vor allem in Zuckerspektrum der aus einseitiger Tracht von einer Pflanzenart stammenden sortenhonige benerkbar machen dürfte. Als Vergleichsbasis diente das Zuckerbild ron Bliitenmischhonigen, an deren Fntstehung mehrere Pflanzenarten beteiligt sind. Ausserdem wurden einige in Zuckerfütterungsversuchen während der Trachtzeit gewonnene Honige in die Cntersuchung einbezogen.

Die Arbeit wurde mit Hilfe der Papierchromatographie ausgeführt, wobei die drei Hauptzucker (Irruktose, (Glukose, Saccharose) quantitativ bestimmt, die übrigen Zuckerarten qualitativ beurteilt wurden. In einer beschränkten Anzahl von I'roben wurden ausserdem Maltose und die höhermolekularen Zuckerarten quantitativ bestimmt. Einzelheiten der angewandten papierchromatographischen Methode sind auf S. 297-299 beschrieben. Zur Untersuchung kan Nektar von 32 Pflanzenarten, $33^{\circ}$ Proben von Blïten-Misch-und-Sortenhonigen aus 23 I,ändern und Io Proben von Zuckerfütterungshonigen. 


\section{Erygantisice.}

I. Jie papierchromatographische Lntersuchung der Nektarproben zeigte, dass das Zuckerspektrum von Pflanzenart zu Pflanzenart sehr verschieden ist. In der Regel enthält der frisch aus der Blïte gewonnene Nektar nur die drei Hauptzucker Iruktose, Glukose, Saccharose ; vereinzelt sind schon im Iirischnektar höhermolekulare Zuckerarten zu finden (z. B. bei I abiaten, Trifolinm pratense, Tilia-Arten). Bei I agerung tritt, in allen Nektararten Hydrolyse ein, wobei höhermolekulare Zuckerarten gebildet werden. I)er Ablauf der Hydrolyse ist von der Iagerungstemperatur abhängig.

In Bezug auf das Mengenverhältnis der drei Hauptzucker lassen sich unter den geprüften Nektararten mehrere (iruppen unterscheiden. Das eine Extrem bilden Rhododendron fermginem und desculus Hippocastanum deren Nektar praktisch nur Saccharose enthält, clas andere Brassica Napus, Pirus communis, Rubus Idaeus und Heraclem Sphondylimm, in deren Nektar hauptsächlich Hexosen und nur sehr wenig Saccharose zu finden ist. In 'Tabelle IX sind die untersuchten Nektararten nach dem mengenmässigen Verhältıis der Hauptzucker in 4 (iruppen eingeteilt. Is geht daraus hervor, dass saccharosereiche und saccharosearme Nektararten annähernd. gleich häufig sind, und dass nahe verwandte Arten sich in dieser Hinsicht oft verschieden verhalten (z. B. Pims-, Prumus-und Tilia-Arten). Das Verhältnis Iiruktose zu Glukose liegt bei der Mehrzahl der untersuchten Xektar-Proben über I,oo, seltener sind Proben mit vorherrschender (Slukose. Auch dieses Verhältnis kann bei nahen verwandten Arten verschieden sein (z. B. Tilia-, Trifolinmund Rubus-Arten).

2. Das Zuckerspektrum der Bliitennischhonige ist das Produkt aus den Zuckerverhältnissen der verschiedenen daran beteiligten Nektararten und der Wirkung der Nektar-und Bienenfermente. Es ist charakterisiert durch annähernd gleiche Werte des I'ruktose-und Glukosegehaltes (i. M. Ir $/(\mathrm{Gl}=\mathrm{I}, 09)$ und niedrige Vierte des Saccharosegehaltes (i. M.

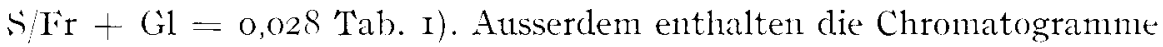
stets $4^{-()}$schwache Flecke höhermolekularer Zucker, die oft in I:orm von Ioppelfecken auftreten und den Zuckern Maltose, Isomaltose, Errose, Kestose, Melezitose und Raffinose entsprechen (Abb. 3). I )iese Verhältnisse ändern sich anch bei längerer I agerung nicht mehr wesentlich, denn das Chromatogranm eines to Jahre alten Honigs zeigt ein ähnliches Zuckerbild (Abb. 4, Tab. II).

3. Ixperinentell durch Zuckerbeifütterung während der 'Trachtzeit gewonnene Zuckerfiutterungshonige sind auf (irund des Zuckerspektrums nicht von reinen Naturhonigen zu unterscheiden (Abb. 5, Tab. II).

4. Abweichungen von diesen durchschnittlichen, für Blütenmisch- 


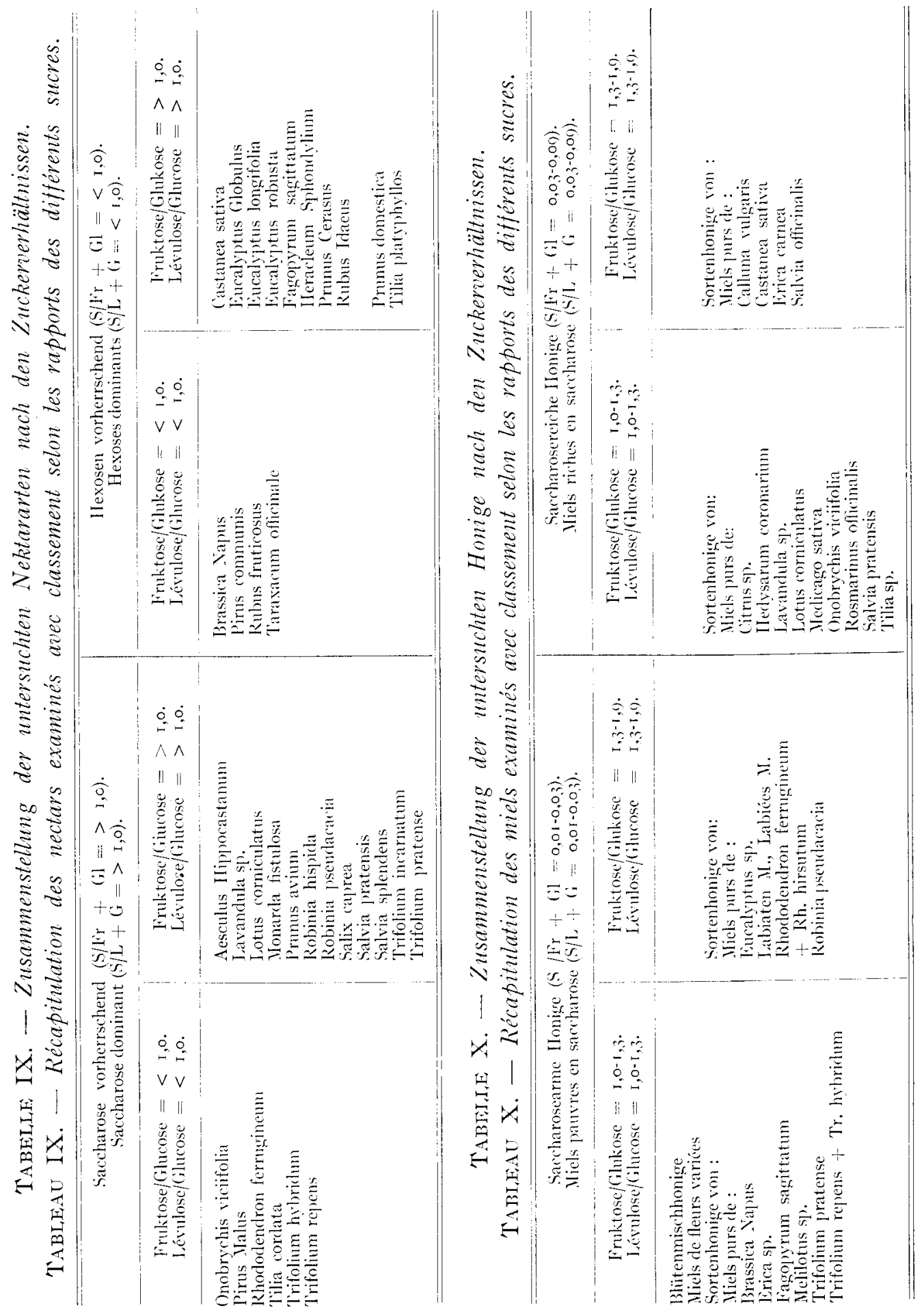


honige charakteristischen Zuckerbild sind bei gewisse Sortenhonigen festzustellen, die aus einseitiger 'Tracht von einzelnen Pflanzenarten stammen. Auf Grund der Zuckerverhältnisse und unter Berïcksichtigung der pollenanalytischen Befunde, lassen sich die untersuchten sortenhonige in folgende Gruppen nuterteilen (Tab. X).

a) Honige mit ansgeglichenen Zuckerverhältnissen (Fr/G1 =-= I,O$\mathrm{I}, 3 ; \mathrm{S} \mathrm{Ir}+(\mathrm{H} 1=0, \mathrm{OI}-\mathrm{O}, \mathrm{O} 3)$. Hierher sind neben den Bliitenmischhonigen zu rechnen : ein Teil der I,eguminosenhonige (IVeissklee-, Rotklee-und steinklee-Honige), die Raps-und Buchweizenhonige und ein einzelner aus Erica-Tracht stammender griechischer Honig.

b) Honige nit niedrigem saccharosegehalt und deutlich höherem Iiruktose-als Glukosegehalt (I'r/G1 $=\mathrm{I}, 3-\mathrm{I}, 9 ; \mathrm{S} / \mathrm{I}$ ir $+\mathrm{G} 1=0, \mathrm{OI}-\mathrm{O}, \mathrm{O} 3)$. In dieser (rruppe sind Honige aus einseitiger 'Tracht von Robinien, Alpenrosen, Eucalyptus und Iabiaten des II(Majorana)- 'Typus zu finden.

c) Honige mit erhöhtem saccharosegehalt und ausgeglichenen Hexosen- Verhältnis ( $\operatorname{Fr}(j 1=I, 0-I, 3 ; S /$ Ir $+(i 1=0,03-0,09)$. I)azu gehört ein 'Teil der I,eguminosenhonige (Hsparsette-, I uzerne-, Hornkleeund Hahnenkammhonige), ein 'Teil cher Iabiatenhonige (Iavendel-und Rosnarinhonige und ein einzelner Miesensalbeihonig), sowie die I,indenund Orangenhonige.

d) Honige mit hohem Saccharosegehalt und höherem Iruktose-als Glukosegehalt ( $\mathrm{Ir} / \mathrm{Gl}=\mathrm{I}, 3-\mathrm{I}, 7 ; \mathrm{S} / \mathrm{Ir}+(\mathrm{H} 1=0,03-0,09)$. Hierher sind zu stellen zwei Iricaceenhonige (Callma und Erica carnea), sowie einseitige Honige von Salia officinalis und Castanea sativa.

e) Honige mit einem unter $I, o$ liegenden Verhältnis Iiruktose Glukose, d. h. mit einem höheren (ilukose-als Iiruktosegehalt, waren in dem von mir verarbeiteten Material selten. Es gehört dazu ein Teil der Rapshonige, sowie einzelne Mischhonige mit hohem prozentualen Anteil ron I,̈wenzahn-und Obstpollen.

5. Soweit die bisherigen Lntersuchungen eine Beurteilung erlauben, scheint im allgemeinen der Maltosegehalt des Honigs höher zu sein als der Saccharosegehalt. In der Regel enthalten Naturhonige 3-6 höhermolekulare Zuckerarten mit niedrigen $\mathrm{R}_{\mathrm{F}}$-Werte11. Besonders hoch ist der (iehalt an Oligosacchariden in I,eguminosen-, I abiaten-, Edelkastanien-, I,inden-, Eucalyptus-und Orangenhonigen.

6. Auf Grund der papierchromatographischen Untersuchung des Nektars verschiedener Pflanzenarten und der dazu gehörenden Sortenhonige, lässt sich in vielen lällen ein Finfluss der Zuckerverhältnisse des Nektars auf das Zuckerbild des fertigen Honigs feststellen. Besonders deutlich ist dieser Finfluss bei Sortenhonigen von Saliia pratensis, Robinia pseudacacia, Brassica Vapus, ('astanea satisa, Tilia und Citrus. Auf die Wirkung der Bieneninvertasen dürfte die Tatsache zurückzuführen sein, dass aus Nektar, der mehr Glukose als Iiruktose enthält, 
Honige mit ausgeglichenem Iruktose (Glukose-Verhältnis entstehen (Tab. IX, X).

7. In vielen Fällen liess sich gute Uebereinstimmung zwischen den Resultaten der papierchromatographischen Untersuchung und den Befunden der quantitativen Pollenanalyse feststellen. So sind z. B. bei den extrem pollenreichen Edelkastanienenhonigen, parallel zum CastaneaPollengehalt deutliche Unterschiede des Zuckerbildes vorhanden; während bei pollenarmen Sorten wie Robinia-, Salvia-, Lavandula-und Citrus-Honige, schon Proben mit geringen prozentualen Anteil der Leit-Pollenform alle charakteristischen Eigenschaften der betreffenden Honigsorte aufweisen ('Tab. III, IV, VII). Keine Uebereinstimmung zwis chen Zuckergehalt und Pollengehalt war dagegen bei den pollenreichen Brassica-Honigen und den pollenarmen Onobrychis-, Tilia-und Medicago-Honigen zu finden ('Tab. III, VII).

8. Aus den angeführten Firgebnissen kann geschlossen werden, dass die papierchromatographische Untersuchung des Zuckerspektrums in gewissen Irällen als Errgänzung der mikroskopischen Prüfung zur Bestimmung der botanischen Herkunft bei Honigen herangezogen werden kann. Man sollte sich dabei aber vor Verallgemeinerungen hiiten und die Befunde von I'all zul I*all, unter Berücksichtignng aller möglichen Tehlerquellen kritisch sichten.

\section{RECHERCHES SUR LES IIIELS ET NECTARS, PAR ChROMATOGRAPHIE SUR PAPIER}

\section{DISCUSSION DES RÉSULTATS ET RÉSUMÉ}

\section{Problèmes et méthodes.}

Dans le présent travail on a examiné principalement les questions suivantes :

a) Des recherches conduites an moyen de la chromatographie sur papier sont-elles susceptibles de mettre en évidence des rapports entre le spectre des sucres du nectar de différentes plantes et le spectre des sucres du miel provenant des mêmes plantes?

b) La chromatographie des sucres du miel fournit-elle un moyen de reconnaître son origine botanique? Cette méthode peut-elle être choisie pour confirmer les données de l'analyse pollinique?

On a admis au départ que l'influence des produits bruts devait pouvoir se faire sentir avant tout sur le spectre des sucres des miels purs provenant de la miellée d'une plante unique. Comme base de comparaison on a utilisé le spectre des sucres du miel mélangé, c'est-à-dire ayant son origine dans des plantes variées. D'autre part, on s'est servi dans 
les recherches de quelques miels obtenus par nourrissement au sucre pendant la miellée.

I e travail a été réalisé au moyen de la chromatographie sur papier ; les trois principaux sucres (lévulose, glucose et saccharose) ont été déterminés quantitativement, les autres sucres n'ont fait l'objet que d'une estimation qualitative. Dans un nombre limité d'échantillons, le maltose et les sucres à poids moléculaire élevé ont été déterminés quantitativement. On trouvera pages 297 à 299 des détails sur les méthodes chromatographiques utilisées. I.es examens ont porté sur le nectar de 32 espèces végétales, sur 330 échantillons de miels purs ou mélangés en provenance de 23 pays ainsi que sur ro échantillons de miel de nourrissement.

\section{RÉSULTATS}

I $^{\circ}$ L'examen chromatographique des nectars montra que le spectre des sucres est très variable d'une plante à l'autre. Enl règle générale, le nectar fraichement récolté sur les fleurs contient seulement les trois sucres principaux, c'est-à-dire le lévulose, le glucose et le saccharose ; parfois, on trouve déjà dans le nectar frais des sucres de poids moléculaire élevé (par exemple chez les Iabiées, Trifolium pratense, Tilia sp.). Au cours de la conservation se produit dans tous les nectars une hydrolyse qui conduit à la formation de sucres à poids moléculaire élevé. Le déroulement de l'hỵdrolyse est sous la dépendance de la température de conservation.

Selon les proportions des trois sucres principaux, on distingue différents groupes parmi les nectars examinés. Un groupe extrême est constitué par les nectars de Rhododendron ferrugineum et d'Aesculus Hippocastanum qui ne contiennent pratiquement que du saccharose; l'autre groupe extrême est constitué par les nectars de Brassica Napus, Pirus communis, Rubus idaeus et Heracleum Sphondylium qui ne contiennent pratiquement que des hexoses et seulement très peu de saccharose. Dans le tableau IX, on trotıvera, séparés en quatre groupes en fonction de leur composition en sucres principaux, les nectars des plantes examinées. Ce tableau permet de constater que les nectars riches en saccharose sont à peu près aussi fréquents que les nectars pauvres en saccharose et que des espèces voisines se comportent souvent très différemment dans ce domaine (par exemple : Pirus, Prumus et Tilia). I, rapport lévulose sur glucose est, dans la plupart des nectars examinés, supérieur à I,OO ; plus rarement on trouve des échantillons avec dominance du glucose. $L_{1}$ e rapport $I / G$ peut être très différent chez des espèces pourtant voisines (par ex. Tilia, Trifolium et Rubus).

$2^{\circ}$ Le spectre des sucres chez les miels de fleurs mélangées est la résultante des proportions des sucres des différents nectars des espèces ayant 
formé le miel et de l'action des ferments des nectars et des Abeilles. Ce spectre est caractérisé par des valeurs approximativement égales de la teneur en lérulose et en glucose (en moyenne $I_{,} G=1,09$ ) et par de faibles valeurs de la teneur en saccharose (en moyenne $S / I_{1}+(\hat{G}=0,028)$ tableau $I$. I) autre part, les chronnatogranmes contiemnent toujours + à 6 petites taches correspondant à des sucres de poids moléculaire élevé, qui souvent apparaissent sous forme double et qui correspondent aux sucres suivants : maltose, isonaltose, erlose, kestose, melezitose et raffinose (fig. 3). Ces proportions se modifient pen sous l'influence de la conservation, même très longue, car le chromatogranme d'un miel vieux de 6o ans montre un spectre des stucres analogue (fig. 4, tableau I).

$3^{\circ}$ I,es miels de nourrissement au sucre, obtenus expérimentalement par nourrissement pendant la période de récolte ne penvent pas être clistingués des miels purs naturels sur la base de leur spectre des sucres (fig. 5 , tableau II).

$4^{\circ}$ Des variations par rapport an spectre moyen des sucres qui caractérise les miels de fleurs mélangées ont été constatées pour certains miels purs provenant de la récolte exclusive sur des espèces végétales déterminées. Compte tenu des proportions des différents sucres et également du spectre pollinique on peut classer les miels purs qui ont été examinés dans les groupes suivants (tableau $\mathrm{X}$ ).

a) Miels où les proportions des différents sucres sont bien égalisées $\left(\mathrm{I}, \mathrm{G}=\mathrm{I}, \mathrm{O}\right.$ à $\mathrm{I}, 3 ; \mathrm{S} \mathrm{I}_{1}+\mathrm{G}=0, \mathrm{OI}$ à 0,03$)$. I) ans ces miels on peut ranger, à côté des miels de fleurs mélangées, une partie des miels de Légumineuses ('Trèfle blanc, Trèfle riolet et IIélilot), les miels de Colza et de Sarrazin ainsi qu'un miel unique d'Erica provenant de Grèce.

b) Miels où la teneur en saccharose est basse tandis que le lévulose l'emporte nettement sur le glucose $(\mathrm{I}, \mathrm{G}=\mathrm{I}, 3$ à $\mathrm{I}, 9 ; \mathrm{S} \mathrm{I}+\mathrm{C}=0, \mathrm{Or}$ à o,03). Dans ce groupe on trouve des miels provenant d'une'récolte unilatérale sur Robinia, Rhododendron, Eucalyptus et Labiées du type II (.Majorana).

c) Miels à teneur en saccharose élevée et proportion égalisée des hexoses $\left(\mathrm{I}_{d} \mathrm{G}=\mathrm{I}\right.$ à $\mathrm{I}, 03 ; \mathrm{S} / \mathrm{I}_{+}+(\mathbf{r}=0,03$ à 0,09$)$. A ce groupe appartiemnent une partie des miels de Légumineuses (Sainfoin, I duzerne, Lotier et Sainfoin d'Espagne), une partie des miels de Labiées (I avande et Romarin et un miel nnique de sange des prés) ainsi que les miels de Tilleul et d'Oranger.

d) Miels à teneur en saccharose élevée et dominance du lévulose sur le glucose $\left(I_{i} G=I, 3\right.$ à $I, 7 ; S I,+G=0,03$ à 0,09$)$. Ici se placent denx miels d'Ericacées (Calluna et Erica carnea), ainsi que des miels purs de Saliva officinalis et Castanea satiza.

e) I.es miels présentant un rapport lérulose glncose inférieur à I, c'est-à-dire contenant plus de glucose que de lévulose étaient rares 
dans le matériel utilisé. Il s'agissait d'une partie des miels de Colza ainsi que de quelques miels de fleurs mélangées contenant un fort pourcentage de pollen de Pissenlit et d'arbres fruitiers.

$5^{0}$ I)ans la mesure où les recherches effectuées jusqu à présent permettent d'en juger, la teneur ell maltose des miels parait plus élevée que la teneur en saccharosé. İn règle générale les miels naturels contiennent de 3 à 6 stucres à poirls noléculaire élevé avec un faible $R_{r}$. I a toneur en oligosaccharides est particulièrement élevée danss les miels de I.égumineuses, de I abiées, de Châtaignier, de 'Tilleul, d'Inucalyptus et d'Oranger.

fo I,étude par la chromatographie sur papier du nectar de différentes plantes et des miels purs correspondants permet, dans beaucoup de cas, de mettre en évidence une influence des proportions des stucres dans le nectar sur le spectre des sucres du miel élaboré. Cette influence est particulièrement nette pour les miels purs de Salvia pratensis, Robinia pseudacacia, Brassica . Vapus, Castanea sativa, Tilia et Citrus. On peut mettre à l'actif de l'invertase de l'Abeille le fait que le nectar qui contient plus de glucose que de lévulose clonne naissance à un miel qui contient sensiblement autant des deux sucres (tableanx IX et $\mathrm{X}$ ).

$7^{\circ}$ Ians beaucoup de cas, on a pu mettre en éridence une bonne concordance entre less résultats des recherches chromatographiques et cenx de lanalyse pollinique quantitative. Ainsi, par exemple, chez les miels de chàtaignier très riches en pollen, on trouve parallèlement à la teneur en pollen de ('astanea, une différence nette dans le spectre des sucres, tandis que dans les miels paurres en pollen, tels que cenx de Robinia, Salizi, Laiandula et (itrus, des échantillons ne contenant qu'tun faible pourcentage du pollen dominant, présentent déjà toutes les propriétés caractéristiques des miels enl question (tableanx III, IV et VII). Par contre, aucune corrélation entre teneur en sucre et teneur en pollen n'a pu être trouvée che\% les miels riches en pollen cle Brassica ou chez les miels paures d'Onobrychis, Tilia et .Medicago (tableaux III et VII).

80 I.es résultats présentés permettent de conclure qu'il est possible d'utiliser la chromatographie sur papier des sucres pour compléter, dans certains cas, l'examen microscopique en vue de la détermination de l'origine botanique les miels. 11 convient toutefois de se garder des généralisations et les résultats derront toujours être examinés d'un cas à l'autre de façon critique, ent tenant compte des sources possibles d'erreur.

\section{LI'TERA'TLR}

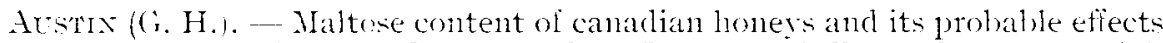
on crystallization. Proi. Io. Imt. Congress of Entomolosy, Montréal, I $95^{(1)}, 4$, IOOI, I $155^{2}$.

BAcox (J. S. I.). Transfuctosiation hy a reast invertase preparation. Bioch. J., 50, XIIII, I052. 
BAcoN (J. S. I).). - The oligosaccharides produced by the action of yeast invertase preparations on sucrose. Bioch. $J ., 5 \%, 320$, I954 $a$; Transfructosidation. Ann. Rep. Chem. Soc. for 1953, 50, 281 , r954b.

BACon (J. S. D.) \& Inickinsox (B.). - The origin of melezitose : a biochemical relationship between the lime tree (Tilia ssp.) and an Aphis (Encallipterus tilix L.). Bioch. $J ., 66,289,1957$.

BACON (J.S. D.) \& EDHIMAN (J.). - The action of invertase preparations. Arch. Bioch., 28, 467, 1950 .

BACON (J.S. D.) \& EDELMAN (J.). - Transfructosidation in extracts of tubers of Helianthus truberosus I. Bioch. J., 49, 520, I05I.

BARTEIs (W.). - Honig und Kunsthonig. Handbuch der L ebensmittelchemie. Springer, Berlin, I938.

BEALING (F. J.). - The transfructosidase activity of mould invertase preparations. Thesis, University of Sheffield, I952.

BEAIING (F. J.) \& BACON (J.S. D).). - The action of mould enzymes on sucrose. Bioch. J., 53, 277, 1953.

Beuti.ir (R.). - Nectar. Bee World, 34, ro6, I953.

BeUtler (R.) \& SchöNTAG (A.). - Ueber die Nektarabscheidung einiger Nutzpflanzen. Z. verg1.Phys., 28, 254, I940.

Beutiter (R.) \& WAHL (O.). - Ueber das Honigen der Linde in Deutschland. Z. iergl. Phys., 23, 30I, I936.

BIANCHARI (P. H.) et Ar,BON (N.). - The inversion of sucrose : a complication. Arch. Bioch., 29, 220, I950.

Bonnier (G.). - I.es nectaires. Thèse, Paris, I879.

Deans (A. S. C.). - Honey analysis. The Scottish Beekeeper, 35, 7, 1959.

Dusprva (F.). - Der Kohlehydratumsatz im Verdauungstrakt der Rhynchoten, ein Beitrag zum Problem der stofflichen Wechselbeziehungen zwischen sautgenden Insekten und Wirtspflanzen. Mitt. Biol. Zentralanstalt Berlin-Dahlem, 75, 82, I953.

DUsPIVA (F.). - Weitere Untersuchungen iiber stoffwechsel-physiologische Beziehungen zwischen Rhynchoten und ihren Wirtspflanzen. Mitt. Biol. Bundesanst. Berlin-Dahlem, 80, I55, I954 a.

Duspiva (F.). - Enzymatische Prozesse bei der Honigtaubildung der Aphiden. Verh. D. Zool. Ges. Tiibingen, 440, I954 b.

E.WAR'T (W. H.) \& Metcalf (R. L.). - Preliminary studies of sugars and amino acids in the honeydews of five species of coccids feeding on Citrus in California. Ann. Ent. Soc. Am., 49, 44I, I956.

FELLENBERG (Th.). - Melezitosehaltige Rottannenhonige der Eirnte I938. Mitt. Geb. Lebensmittelunters. und Hygiene, 29, 27 I, 1938.

FEI,IENBERG (Th.) \& RUFFY (J.). - Untersuchungen iber die Zusammensetzung echter Bienenhonige. Mitt. Lebensmittelunters. und Hygiene, 24, 367,1933 .

FioOd (A. E.), HiRs' (E. L.) \& JoNes (J. K. N.). - Quantitative estimation of mixtures of sugars by the paper chromatography method. Nature, $\mathbf{1 6 0}, 86, \mathrm{I} 947$.

Furgala (B.), Gochatule ('l'. A.) \& Hom, Hay (F. G.). - Constituent sugars of some northern legume nectars. Bee World, 39, 203 , 1958.

GEInitz (B.). - Die Entstehung des Tannenhonigs. Arch. t. Bienenk., 11, 308 , I930.

Gomplinmer (St.) \& Burkint (H.). - - Ueber das Vorkommen einiger im Bienenhonig bisher unbekannter Zucker. Hoppe Sevley's Z. t. phys. Chemie, 300, I88, I 955 .

Gontarski (H.). - Fermentbiologische Studien an Bienen. 1. Das physikochemische Verhalten der Kohlehydrat spaltenden Fermente : a) invertierende Fnzyme. Terh. I. Ges. ang. Entomol. e. T., IS6, I954. 
GORIACH (G.). - Ernährungsphysiologische Studien an der Biene. Forschungsdienst, 11, 210, I94I.

Gray (H. E.) \& Fratikn. (G.). - Fruktomaltose, a recently discovered trisaccharide isolated from honeydew. Science, 118, 304, I953.

Gray (H. E.) \& Fratexkei. (G.). - The carbohydrate components of honeydew. Phys. Zool., 27, 56, I954.

GRAY (R. A.). - Composition of honeydew excreted by pineapple mealybugs. Science, 115, I29, 1952.

Lixskexs (H. F.). - Papierchromatographie in der Botanik. Springer, Berlin, I 959 .

LCXiper (R.). - Jer Einfluss von Honiglösapparaten auf das Pollenbild des Heidehonigs. Z. f. Bienenforsch., 3, 49, I955.

MaI, отн (E.). - Zur papierchromatographischen Jarstellung des Honigs. Naturwiss., 38, 478, I95I.

Mavrizio (A.). - - Beiträge zur quantitativen Pollenanalyse des Honigs. Beih. Schweiz. Bienenztg., 2, 320, I949.

Maurizio (A.). - Untersuchungen über die Herkunft und Wirkung der invertierenden Fermente im Honig. Ber. 15. intern. Bienenzüchterkongress, Kopenhagen, Res., 40, I954 a.

Maurizio (A.). - Untersuchungen über die Nektarsekretion einiger polyploider Kulturpflanzen. Arch. J. Klaus-Stiftung, 29, 340, I954 b.

Maurizro (A.). - Beiträge zur quantitativen Pollenanalyse des Honigs. 2. Absoluter Gehalt pflanzlicher Bestandteile in Tilia- und Labiatenhonigen. Z. $f$. Bienenforschung, 3, 32, I955.

Maurizio (A.). - Zuckerabbau unter der Einwirkung der invertierenden Fermente in Pharynxdrïse und Mitteldarm der Honigbiene (Apis mell. I.). I. Sommerbienen der Krainer- und Nigra-Rasse. Insectes Soc., 4, 225, I957.

MaUrizio (A.). - Beiträge zur quantitativen Pollenanalyse res Honigs. 2. Absoluter Gehalt planzlicher Bestandteile in Esparsette-, Luzerne-, Orangen- und Rapshonigen. Annales de l'A beilie, 1, 93, I958.

MaUrizio (A.). - Breakdown of sugars by inverting enzymes in the pharyngeal glands and mitgut of the honeybee. 2. Winter bees (Carniolan and Nigra). Bee World, 40, 275, 1959.

Mc. Doxaln (E. J.). - Quantitative chromatographic procedure for determining dextrose in sugar mixtures. An. Chem., 29, 32, 1957 .

Nerson (N.). - A photometric adaptation of the Somogyi method for the determination of glicose. J. Biol. Chem., 153, 375, I944.

Noтвонм (E.) \& I ucius (F.). - Melezitose im Honigtau der I.inde. Z. Unt. Lebensm., 5\%, 549, 1929.

PARkER (J.). - Changes in sugar and nitrogenous compounds of tree barks from summer to winter. Naturwiss., 45, I39, I958.

PARTRIDGE (S. M.) \& WESTALL (R. G.). - Filter paper chromatography of sugars. Bioch. J., 42, 238 , I948.

PAzCR (J.H.) \& FRFNCH (I).). - The transglucosidase of Aspergillus oryzae. J. Amer. Chem. Soc., \%3, 3536, I95I.

Pianta (A. v.). - Die Zusammensetzung einiger Nektar-Arten. Schweiz. Bionenztg., 9, 217 , I886.

Pritsch (G.). - Zum Problem der mikroskopischen Pollenanalyse des Bienenhonigs. Wiss. Zeitschr. d. Humboldt-Universtität, Berlin, 6, I97, I957.

Sur.ser (H.). - Quantitative Papierchromatographie mit dem photoelektrischen Leukometer. 7. Mitteilung übar Anwendung der Papierchromatographie auf lebensmittelchemische Probleme. Mitt. Lebensmittelunters. und Hygiene, 45, 5I7, I954.

Tüurê. (K.) \& MüirLer (K.). -Zur Herkunft der Sacharide im Honig. Zeitschr. t. Lehensm. Unt. Forschung, 96, 8., r953. 
'lärris. (K.) \& Rriss (R.). - Analytische und chronatographische Studien am Bienenhonig. \%. Lelonsm. Unt. Forschung, 94, I, 1952.

Vinser, (G. H.). - Cotton nectar in relation to bee activity and honey pro(luction. J. Ec. Ent., 3\%, 528, I944a.

VAxist. (G. H.). - Some western nectars and their corresponding honeys. J. Ec. Ent., 3\%, 530, 1944 b.

Vaxisto (G. H.) \& WA'kixs (W. (G.). - Orange nectar and pollen in relation to bee activity. J. Ec. Ent., 35, $32 \mathrm{I}, \mathrm{I} 942$.

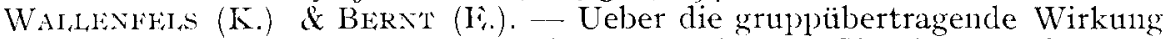
rou disaccharid-spaltenden tinzymen. Angea'. Chemie, 64, 28, 1952 .

WhILENFEIS (K.), BERNT (Ii.) \& IIMBERG (G.). - Isolierung von Lactotriose, Iactobiose and Galaktobiose aus dem enzymatischen Hychrolysat von Lactose. Lieligs Ann. Chem., 579, I13, I953.

WANNLR (H.). - I Ia Zusammensetzung des Siebröhrensaftes : Kohlehydrate. Ber. Schaeiz. Bot. Cos., 63, I62, I953 a.

Wanvir (H.).-Enzyme der Glykolyse im Phloemsaft. Ber. Schweiz. Bot. Ges., 63, $201,1953 b$.

Whise (J. W. ). -- The action of invertase preparations. Arch. Bioch., 39, 238, I952. The composition of honey. Bec World, 38, 57, I957.

Whini: (J. W. \& MaHer (J.) - $\boldsymbol{\alpha}$-Maltosyl- $\beta$-Fructofuranoside, a trisaccharide enzymatically synthezised from sucrose. J. Amer. Chem. Soc., 75, I2.59, I053 a.

Wnim: (J. W.). I Maher. (J.) - 'Transglucosidation by honey invertase. Arch. Bioch., 42, 360, 19536 .

WhitT: (J. W.). \& MaHêR. (J.) - Sugar analyses of honey by a selective adsorption method. I. Ass. Off. Agric. Chem., 37, 478 , I954.

WoII (J. P. III) \& I.WAR'T (W. H.). - Carbohydrate composition of the honeydew of Coccus hesperidum L. : Evidence for the existence of two new oligosaccharicles. Arch. Bioch. Biophys., 58, 365, 1955.

Wraks (G. R.). - - An investigation of the sugars present in the nectar of flowers of various species. The New Phytologist, 51, 2 10, 1952.

Wykes (G. R.). - The sugar content of nectars. Bioch. J., 53, 294, 1953.

ZANDER (E.). - Beiträge zur Herkunfstbestimmung bei Honig. Pollengestaltung und Herkunftsbestimmung bei Blütenhonig. I, Berlin I935, II, III, I.eipzig I937, I94I.

Zakilis (H.). - Tntersuchungen über die I,eitung und Sekretion der Assimilate. Planta, 4\%, 447, I956.

Zimmikmase (M. H.). - Papierchromatographische Untersuchungen iiber pflanzliche Zuckersekretion. Ber. Schreiz. Bot. Ges., 63, 402, 1953.

ZimmermanN (M. H.). - Ueber die Sekretion saccharosespaltender 'Iransglukosidasen im pflanzlichen Nektar. Experientia, 10, I45, I954.

ZIMMERMAN (M. H.). - Translocation of organic substances in trees. I. The nature of the sugars in the sieve tube exudate of trees. Plant I'hysiol., $32,288,1957 a$.

'LimMLimand (M. H.). -- II. 'Translocation mechanism in the phloen of white ash (Fraxinus americana L.). Plant Physiol., 32, 399, I957 b.

Zimmermaxi (M. H.). -.. III. The removal of sugars from the sieve tube in the white ash (Fraxinus americana I.). Plant. 1'hysiol., 33, 2 I3, I958 a.

ZrMmermanx (M. H.). -- Translocation of organic substances in the phloem of trees. The Physiol. of Forest Trees, Ronald Press Co. N. Y., 38 I, I 958 b.

Zussir (H. K.). - The sugar composition of honey. Chom. Abstr., 52, $7566 \mathrm{~h}$, 1958 . 